\title{
AMPK activation inhibits the functions of myeloid-derived suppressor cells (MDSC): impact on cancer and aging
}

\author{
Antero Salminen $^{1} \cdot$ Anu Kauppinen ${ }^{2} \cdot$ Kai Kaarniranta ${ }^{3,4}$ \\ Received: 11 March 2019 / Revised: 10 April 2019 / Accepted: 8 May 2019 / Published online: 25 May 2019 \\ (C) The Author(s) 2019
}

\begin{abstract}
AMP-activated protein kinase (AMPK) has a crucial role not only in the regulation of tissue energy metabolism but it can also control immune responses through its cooperation with immune signaling pathways, thus affecting immunometabolism and the functions of immune cells. It is known that AMPK signaling inhibits the activity of the NF- $\mathrm{KB}$ system and thus suppresses proinflammatory responses. Interestingly, AMPK activation can inhibit several major immune signaling pathways, e.g., the JAKSTAT, NF- $\mathrm{BB}, \mathrm{C} / \mathrm{EBP} \beta, \mathrm{CHOP}$, and HIF- $1 \alpha$ pathways, which induce the expansion and activation of myeloid-derived suppressor cells (MDSC). MDSCs induce an immunosuppressive microenvironment in tumors and thus allow the escape of tumor cells from immune surveillance. Chronic inflammation has a key role in the expansion and activation of MDSCs in both tumors and inflammatory disorders. The numbers of MDSCs also significantly increase during the aging process concurrently with the immunosenescence associated with chronic low-grade inflammation. Increased fatty acid oxidation and lactate produced by aerobic glycolysis are important immunometabolic enhancers of MDSC functions. However, it seems that AMPK signaling regulates the functions of MDSCs in a context-dependent manner. Currently, the activators of AMPK signaling are promising drug candidates for cancer therapy and possibly for the extension of healthspan and lifespan. We will describe in detail the AMPK-mediated regulation of the signaling pathways controlling the expansion and activation of immunosuppressive MDSCs. We will propose that the beneficial effects mediated by AMPK activation, e.g., in cancers and the aging process, could be induced by the inhibition of MDSC functions.
\end{abstract}

Keywords Aging $\cdot$ Immunosuppression $\cdot$ Immunosenescence $\cdot$ Immunotherapy $\cdot$ Longevity $\cdot$ Trained immunity

\section{Introduction}

AMP-activated protein kinase (AMPK) acts at the nexus of the regulation of energy metabolism and immune responses, with involvements in the activities of both innate and adaptive

Antero Salminen

antero.salminen@uef.fi

1 Department of Neurology, Institute of Clinical Medicine, University of Eastern Finland, P.O. Box 1627, FI-70211 Kuopio, Finland

2 School of Pharmacy, Faculty of Health Sciences, University of Eastern Finland, P.O. Box 1627, FI-70211 Kuopio, Finland

3 Department of Ophthalmology, Institute of Clinical Medicine, University of Eastern Finland, P.O. Box 1627, FI-70211 Kuopio, Finland

4 Department of Ophthalmology, Kuopio University Hospital, P.O. Box 100, FI-70029 Kuopio, Finland immunity [1,2]. AMPK activation regulates cellular immunity in cooperation with immune signaling pathways and controlling energy metabolism which consequently affects the activation of immune cells. Since AMPK signaling maintains cellular homeostasis, it is not surprising that its function is disturbed in many chronic diseases [3, 4]. However, it seems that the regulation of AMPK signaling is a complex and context-dependent process which can generate even opposite effects in chronic diseases, e.g., in tumorigenesis [5]. It is known that AMPK activation can suppress inflammatory responses by inhibiting the functions of two major immune signaling pathways, i.e., nuclear factor- $\mathrm{KB}(\mathrm{NF}-\mathrm{kB})$ and signal transducer and activator of transcription (STAT) pathways $[6,7]$. Interestingly, the same signaling pathways control the expansion and activation of myeloid-derived suppressor cells (MDSC) which induce an immunosuppressive microenvironment around tumors and thus allow tumor cells to escape from immune surveillance $[8,9]$. The numbers of MDSCs also increase with aging concurrently with the immunosenescence 
associated with a low-grade inflammation $[10,11]$. There is convincing evidence that AMPK activation can inhibit tumor growth and even extend the healthspan and lifespan (see below). We will examine in detail the repressive effects of AMPK signaling on the expansion of MDSCs and their activation and functions in inflamed tissues, such as tumors and aging tissues.

\section{AMPK controls energy metabolism and immune responses}

AMPK signaling not only has a crucial role in energy metabolism but it also undertakes a close crosstalk with other signaling pathways in order to maintain tissue homeostasis in the face of diverse stresses $[12,13]$. AMPK activation stimulates energy production through glucose and fatty acid oxidation, whereas it inhibits anabolic processes, e.g., glycogen synthesis, gluconeogenesis, as well as fatty acid and cholesterol syntheses. Nonetheless, there exist distinct tissue-specific differences in the functions of AMPK. The major activators of AMPK are (i) liver kinase B1 (LKB1), activated by AMP and (ii) $\mathrm{Ca}^{2+} /$ calmodulin-dependent protein kinase $\beta$ $(\mathrm{CaMKK} \beta)$, stimulated by increased $\mathrm{Ca}^{2+}$ concentration. There are a number of downstream targets for AMPK signaling, typically the enzymes controlling energy metabolism, cell growth, and autophagy. AMPK activation also regulates the functions of many transcription factors, in either a direct or indirect manner. In addition to energy metabolism, AMPK signaling controls the proteostasis of cells, i.e., it inhibits mammalian target of rapamycin (mTOR) thus reducing protein synthesis but in contrast, it activates autophagic degradation via the stimulation of ULK1 [14]. Accordingly, AMPK signaling has a crucial role in tumor growth $[5,15]$ and the aging process $[16,17]$.

There is convincing evidence that AMPK activation prevents inflammatory responses through the inhibition of proinflammatory signaling pathways $[1,6]$. For instance, the activation of AMPK inhibits the function of the NF- $\mathrm{kB}$ system as well as JAK-STAT signaling, both of which are major pathways of inflammatory and immune responses $[6,7]$. In macrophages, the activation of AMPK promotes the polarization of M1 pro-inflammatory macrophages towards the M2 antiinflammatory phenotype [18]. Moreover, AMPK activation regulates the signaling of the anti-inflammatory cytokine, IL-10, in macrophages, e.g., enhancing the IL-10-induced suppression of LPS-stimulated cytokine production [19]. Ishii et al. [20] demonstrated that the activation of AMPK suppressed the proliferation of macrophages induced by oxidized low-density lipoprotein (Ox-LDL). They also reported that AMPK activation inhibited the Ox-LDL-induced expression of granulocyte-macrophage colony-stimulating factor (GM-CSF). This is an important observation since GM-CSF is a potent inducer of MDSC generation in the bone marrow
$[9,21]$. Several studies have also demonstrated that the activation of AMPK has an important role in the differentiation and functions of $\mathrm{T}$ lymphocytes by regulating their energy metabolism $[2,22]$. These observations clearly indicate that AMPK signaling controls the balance between energy metabolism and immune responses.

\section{MDSCs are inducers of immunosuppression}

By definition, MDSCs are immature myeloid cells which display immune suppressive properties against adaptive and innate immunity $[8,9]$. MDSCs originate from hematopoietic stem cells through the lineage of common myeloid progenitors in the bone marrow. Several pathological conditions in the body, e.g., tumorigenesis and inflammatory disorders, are known to trigger emergency myelopoiesis which stimulates the proliferation of immature myeloid cells (IMC), the progenitors of MDSCs, in the bone marrow and consequently IMCs can migrate into extramedullary sites, e.g., spleen and lymph nodes. The emergency signaling originating from tumors and inflamed tissues stimulates the differentiation of IMCs into MDSCs and promotes their expansion. For instance, colony-stimulating factors, e.g., GM-CSF and GCSF, stimulate emergency myelopoiesis and thus trigger the differentiation and expansion of MDSCs through the regulation of STAT signaling pathways $[23,24]$. The chemotaxis of MDSCs into tumors and inflamed tissues is driven by several chemokines, e.g., CC ligand 2 (CCL2), CXC chemokine ligand 2 (CXCL2), and CXCL8/IL-8. In inflamed tissues, the microenvironmental conditions control the proliferation of MDSCs and the induction of their immune suppressive activities $[8,10,25,26]$. Several cytokines, e.g., IL-1 $\beta$, IL-6, IL18 , and TNF- $\alpha$, as well as some alarmins, such as HMGB1 and S100A8 and A9, are potent enhancers of immunosuppressive properties of MDSCs. These inflammatory mediators stimulate the expression immunosuppressive genes through distinct transcription factors, e.g., STATs, NF-kB, and HIF$1 \alpha$ pathways. There are two different phenotypes of MDSCs, i.e., monocytic and granulocytic MDSCs, which not only display differences in their generation but they also possess distinct immunosuppressive phenotypes [25, 27, 28]. However, the functional differences need to be clarified since most studies investigating MDSCs have not differentiated between these two phenotypes.

MDSCs are immunosuppressive cells which suppress mainly the functions of $\mathrm{T}$ and $\mathrm{B}$ lymphocytes but they can also inhibit the innate immunity responses of myeloid cells $[8,27,29]$. MDSCs possess the potent immune suppressive armament with different inhibitory mechanisms, as described in detail elsewhere $[8,27,30]$. MDSCs secrete several antiinflammatory cytokines, such as TGF- $\beta$ and IL-10; not only do these factors inhibit immune responses but they are also able to enhance the functions of other immunosuppressive 
cells, e.g., regulatory T cells (Tregs) and B cells (Bregs) $[31$, 32]. For instance, the presence of TGF- $\beta$ and IL-10 inhibits the proliferation and functions of $\mathrm{T}$ and $\mathrm{B}$ cells $[31,33]$. Moreover, these cytokines can induce the alternative polarization of proinflammatory M1 macrophages towards the antiinflammatory M2 phenotype [31]. MDSCs also secrete reactive oxygen species (ROS) and thus suppress the functions of immune cells $[30,34]$. The activation of MDSCs induces the expression of NADPH oxidase (NOX2) and inducible nitric oxide synthase (iNOS) which generates different ROS compounds and nitric oxide (NO). It is known that the product of $\mathrm{H}_{2} \mathrm{O}_{2}$ and $\mathrm{NO}$, i.e., peroxynitrite $\left(\mathrm{ONOO}^{-}\right)$, is able to nitrate the tyrosine residues of $\mathrm{T}$ cell receptor (TCR) after which the receptor no longer recognizes antigen peptides and thus the TCR signaling pathway is inhibited [35]. MDSCs also promote immunosuppression since they induce the expression of amino acid metabolizing enzymes leading to a shortage of critical amino acids in the inflammatory microenvironment [36]. Arginase 1 (ARG1) and indoleamine 2,3-dioxygenase (IDO) catabolize arginine and tryptophan, respectively, which inhibit protein synthesis and subsequently, impair the functions of immune cells. MDSCs can also suppress immune functions in a contact-dependent manner through the socalled checkpoint receptors. The activation of MDSCs stimulates the expression of programmed death-ligand (PD-L1) receptor which binds to the PD-1 receptor, e.g., in T cells and macrophages $[37,38]$. Currently, the immunotherapy of PDL1 blockade is viewed as a promising treatment in many cancers [39].

The activation of emergency myelopoiesis not only generates proinflammatory myeloid cells but it also stimulates the production of immunosuppressive MDSCs [9, 40, 41]. In inflamed tissues, MDSCs have an important role in the resolution of inflammation $[41,42]$. In particular, the secretion of IL10 and TGF- $\beta$ increases the phagocytic activity of macrophages. Saiwai et al. [42] demonstrated that MDSCs enhanced the resolution process of acute inflammation after spinal cord injury (SCI) in mice. Infiltrated MDSCs accelerated the removal of hematomas and tissue debris as well as stimulating angiogenesis after SCI. They also reported that the transplanted MDSCs promoted the repair process and the recovery of functional properties in mouse SCI. However, in chronic inflammatory disorders, where the perpetrator has not been removed, e.g., in tumors, chronic infections, autoimmune diseases, and many degenerative diseases, MDSCs suppress the functions of immune cells of both adaptive and innate immunity, thus aggravating the pathological condition. The immunosuppressive state has been associated with different kinds of pathology, e.g., tumors, stroke, and sepsis [27, 43, 44]. Immunosenescence, a phenomenon linked to the aging process, causes many similar alterations appearing in an immunosuppressive state in many inflammatory disorders $[11$, 45].

\section{Role of MDSCs in tumor growth and aging process}

Over 20 years ago, it was discovered that there was a clear association between the presence of MDSCs, earlier called null cells and veto cells, and tumor growth and the escape of tumor cells from immune surveillance [46]. Subsequently, it was observed that inflammation had a crucial role in the expansion and recruitment of MDSCs into tumors and inflamed tissues. Bunt et al. [47] demonstrated that the inoculation of the IL-1 $\beta$-promoted $4 \mathrm{~T} 1$ mammary carcinoma cells into mice increased the infiltration of MDSCs into tumor sites, whereas the accumulation of MDSCs into tumors was clearly delayed in the IL-1 receptor-deficient mice which also displayed reduced tumor growth. Subsequently, the key role of inflammation has been verified in both tumorigenesis and the MDSCmediated tumor tolerance [27, 48]. As described above, MDSCs possess different immunosuppressive properties which are able to overcome the antitumor immune reactions mediated by $\mathrm{T}$ cells and natural killer (NK) cells. In cooperation with Tregs and tumor-associated macrophages (TAM), MDSCs reduce the proliferation of CD4 and CD8 T cells and NK cells, as well as inhibiting the cytotoxicity of CD8 T and NK cells. Multiple strategies have been developed to inhibit the immune suppressive functions of MDSCs in tumors $[49,50]$. For instance, there has been a search for potent inhibitors of the major signaling pathways which regulate the immune suppressive properties of MDSCs. Two STAT3 inhibitors, sunitinib and axitinib, were reported to inhibit the recruitment of MDSCs into tumors and to suppress the functions of T cells [51, 52]. Interestingly, it is known that several phytochemicals which are inhibitors of STAT3 and NF- $\mathrm{kB}$ signaling also suppress the expansion and activation of MDSCs and thus enhance antitumor immunity, at least in mice [53]. Given that MDSCs are immature cells, there are some observations that all-trans retinoic acid (ATRA) and $\beta$-glucan can induce the maturation of MDSCs and thus enhance antitumor activity $[54,55]$.

The aging process is associated with chronic low-grade inflammation, a condition which has been called inflammaging [56]. Simultaneously, there are antiinflammatory processes, accordingly termed antiinflammaging [57]. Intriguingly, the human immune system is suppressed with aging affecting especially $\mathrm{T}$ and $\mathrm{B}$ lymphocytes, although clear age-related changes also occur in the functions of innate immunity [58]. Currently, the origin of the immunosenescence is not known although many of the changes are similar to those induced by MDSCs [11]. There is convincing evidence that the numbers of MDSCs substantially increase with aging in the bone marrow, blood, spleen, and peripheral lymph nodes. The age-related expansion of MDSCs has been observed in humans [59,60] and mice [61-63]. An increased level of MDSCs has also been detected in 
progeroid mice [63]. The inflammaging process also affects the bone marrow which might induce aberrant myelopoiesis [64]. There is a clear increase in myelopoiesis with aging [65] which could be induced by the TGF- $\beta$, secreted from MDSCs, since TGF- $\beta$ signaling enhances the myeloid differentiation of mouse hematopoietic stem cell clones [66]. It seems that the expansion of MDSCs with aging might not only promote immunosenescence but also induce age-related harmful bystander effects in host tissues via the secretion of TGF- $\beta$ and IL-10 as well as provoking a shortage of distinct amino acids [10].

\section{AMPK signaling is potential regulator of MDSC functions}

There are several studies indicating that AMPK activators can inhibit the functions of MDSCs and display antitumor activities in many cancers [67-69]. For instance, Trikha et al. [67] demonstrated that OSU-53 treatment, an AMPK activator [70], reduced the numbers of MDSCs in both the spleen and tumors of carcinoma-bearing mice. Simultaneously, administration of OSU-53 increased the numbers of T cells and NK cells in the spleen and tumors. Moreover, treatment with metformin, another AMPK activator, reduced the accumulation of MDSCs into esophageal tumors by inhibiting NF- $\mathrm{KB}$ signaling in an AMPK-dependent manner [68]. AMPK signaling can also control energy metabolism and immune processes in cooperation with several other signaling pathways. We will elucidate the association of AMPK activation with the signaling mechanisms which control the expansion and activation of MDSCs. It seems that AMPK signaling is able to inhibit the

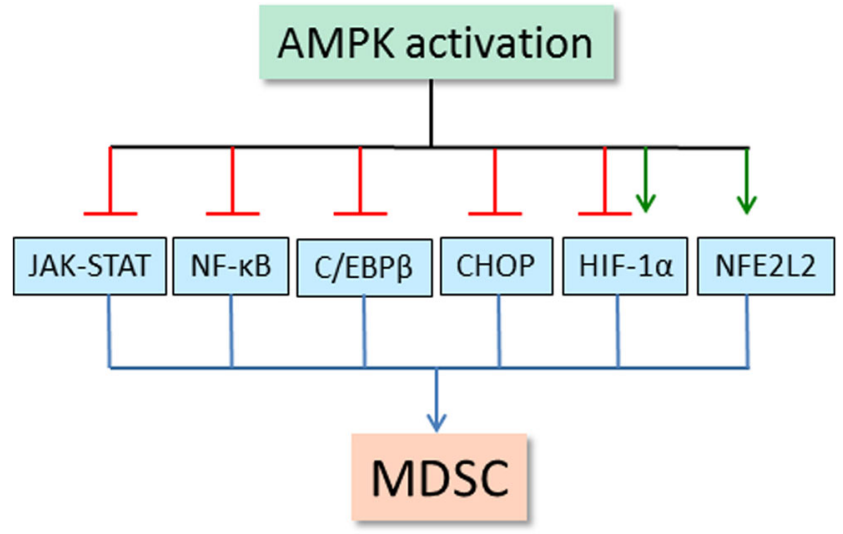

Fig. 1 Schematic presentation depicting the signaling connections through which AMPK signaling controls the major activation pathways of MDSCs. A stopper indicates an inhibitory connection and an arrow denotes an activating pathway. Abbreviations: AMPK, AMP-activated protein kinase; $\mathrm{C} / \mathrm{EBP} \beta, \mathrm{CCAAT}-\mathrm{C}$ hancer-binding protein $\beta$; $\mathrm{CHOP}$, C/EBP homologous protein; HIF- $1 \alpha$, hypoxia-inducible factor- $1 \alpha$; JAK, Janus kinase; MDSC, myeloid-derived suppressor cell; NF-kB, nuclear factor-kB; NFE2L2, nuclear factor (erythroid derived 2)-like 2; STAT, signal transducer and activator of transcription major immune signaling pathways, such as the JAK-STAT, NF- $k B, C / E B P \beta, C H O P$, and HIF- $1 \alpha$ pathways, all of which stimulate the functions of immunosuppressive MDSCs (Fig. 1).

\section{JAK-STAT3 pathway}

The JAK-STAT3 signaling pathway has a crucial role in the regulation of immune responses in both the innate and adaptive immune systems [71]. It is known that the STAT3 transcription factor regulates the expression of tens of cytokines and growth factors; thus they can control immune responses and induce the immune escape of tumors. Ko and Kim [24] have reviewed several specific STAT-mediated signaling pathways which induce the generation and activation of MDSCs in mouse and human cancers. In addition to STAT3, other STATs, i.e., STAT1, STAT5, and STAT6, can also enhance the functions of MDSCs. The most important MDSC-related inducers of STAT signaling are GM-CSF, G-CSF, IL-4, IL-6, IL-10, and VEGF. Interestingly, polyunsaturated fatty acids (PUFA) also promoted the expansion of MDSCs via JAK-

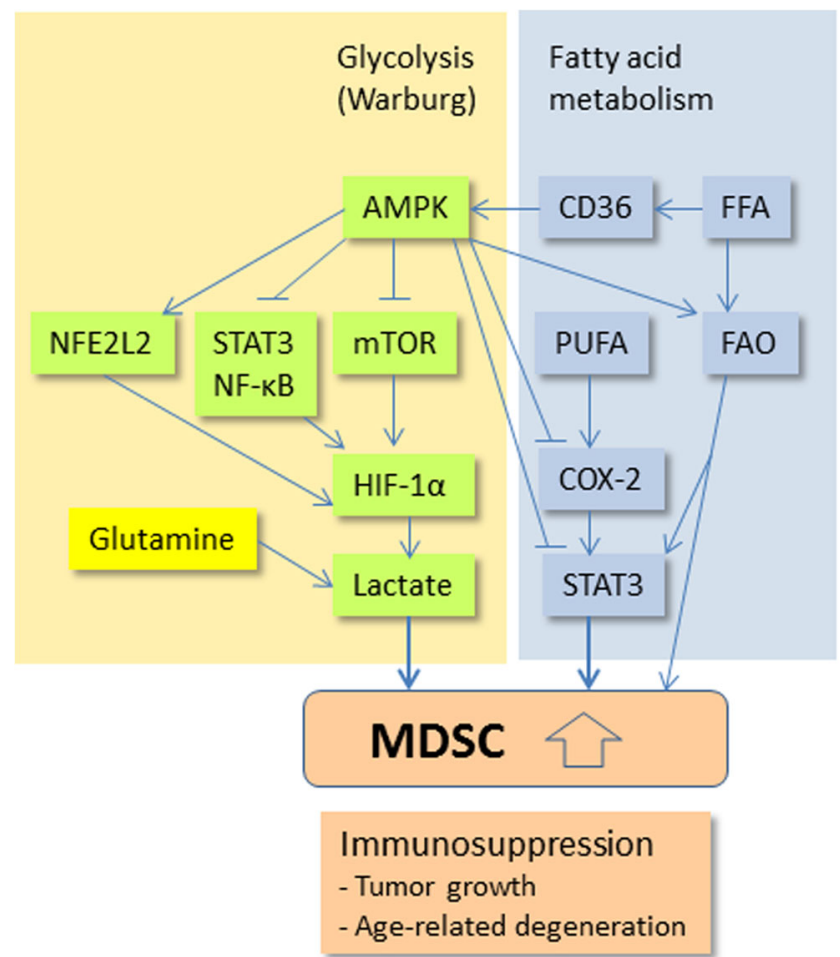

Fig. 2 Schematic presentation depicting the energy metabolic pathways through which AMPK controls the activation of MDSCs. The metabolic pathways linked to the aerobic glycolysis and fatty acid metabolism have been described. A stopper indicates an inhibitory connection and an arrow denotes an activating pathway. Increased MDSC activation generates an immunosuppressive state which enhances tumor growth and age-related degeneration in tissues. Abbreviations: CD36, cluster of differentiation 36; COX-2, cyclooxygenase-2; FAO, fatty acid oxidation; FFA, free fatty acid; PUFA, polyunsaturated fatty acid. Other abbreviations are as marked in Fig. 1 
STAT3 signaling in mice [72] (Fig. 2). Consequently, the JAK-STAT3 pathway stimulated the immune suppressive activities of MDSCs by inducing the expression of ARG1 [73], IDO [74], iNOS [75], and PD-L1 [76]. Waight et al. [23] demonstrated that G-CSF and GM-CSF increased the generation of MDSCs by downregulating the expression of IRF-8 in myeloid progenitors via signaling through STAT3 and STAT5 pathways. Correspondingly, a deficiency of IRF-8 provoked the expansion of the MDSC population in mice. On the other hand, Kumar et al. [77] revealed that the inhibition of STAT3 signaling in mouse MDSCs through the activation of CD45 phosphatase induced the differentiation of MDSCs into TAMs. The inhibition of STAT3 signaling by sunitinib arrested the proliferation and reduced the viability of splenic MDSCs in tumor-bearing mice [78]. There are also several phytochemicals, e.g., curcumin, which have been reported to suppress the functions of MDSCs by inhibiting STAT3 signaling [53]. These observations provide compelling evidence that the JAK-STAT3 pathway has a crucial role in both the differentiation and immunosuppressive properties of MDSCs.

There is substantial evidence that the activation of AMPK signaling inhibits the JAK-STAT pathway and affects many immune responses. For instance, Rutherford et al. [7] revealed that AMPK activation inhibited the activity of Janus kinase 1 (JAK1) by directly phosphorylating the protein on $\mathrm{Ser}^{515}$ and $\mathrm{Ser}^{518}$ residues in intact cells. Consequently, the phosphorylation of JAK1 prevented the STAT3-dependent gene expression, e.g., the IL-6-induced responses. The inhibitors of JAK kinases, i.e., jakinibs, are claimed to be promising drugs in inflammatory and autoimmune diseases [79]. Interestingly, IL-6 and many other cytokines are potent inducers of the development as well as the activation of MDSCs (see above). There are also other AMPK-dependent mechanisms which can suppress the JAK-STAT pathways, e.g., AMPK activation can attenuate the nuclear translocation of STAT1 and thus inhibit the INF- $\gamma$-induced signaling [80]. Nerstedt et al. [81] demonstrated that the activation of AMPK by AICAR and metformin inhibited the IL-6-induced phosphorylation of STAT3. It needs to be recognized that AMPK signaling can also inhibit STAT3 factor through indirect pathways, e.g., by activating SIRT1 [82] which is a well-known target of AMPK signaling. Moreover, He et al. [83] reported that AMPK activation suppressed STAT1 signaling by increasing the expression of mitogen-activated protein kinase phosphatase-1 (MKP-1). Currently, it is known that AMPK activators can alleviate many chronic diseases, e.g., rheumatoid arthritis and chronic infections, which are associated with an overstimulation of the JAK-STAT signaling $[84,85]$. Considering that MDSCs induce immunosuppression in chronic inflammatory diseases, it seems likely that the activation of AMPK signaling could alleviate the MDSC-induced immunosuppression by inhibiting the JAK-STAT signaling.

\section{NF-KB system}

The NF- KB signaling pathway does not only regulate the immune responses but it also controls the development of myeloid cells, e.g., MDSCs and Tregs [86, 87]. There is convincing evidence that many inflammatory mediators, e.g., IL-1 $\beta$, IL-6, and TNF- $\alpha$, can augment the differentiation of MDSCs and stimulate their immunosuppressive properties (see above). Moreover, some alarmins, e.g., HMGB1 and S100A8 and A9, have been reported to enhance the immune suppressive properties of MDSCs in inflamed tissues [88, 89]. All these inflammatory factors are potent activators of the $\mathrm{NF}-\mathrm{KB}$ pathway, which indicates that NF- $\mathrm{KB}$ signaling has an important role in the expansion of MDSCs in inflamed tissues. NF- $\mathrm{KB}$ signaling also has a crucial role in tumor initiation and progression [90]. Bunt et al. [91] demonstrated that the pro-inflammatory factors released by tumors induced the accumulation and activation of MDSCs, thus enhancing immune suppression and the immune escape of tumors. Recently, Flores et al. [63] revealed that the numbers of MDSCs significantly increased with aging in mouse bone marrow and spleen through the NF-KB-dependent mechanism. Given that MDSCs display a robust level of NF- $\mathrm{KB}$ activity, it seems that NF-KB signaling also induces the expansion of MDSCs during the inflammaging process. Moreover, Zhang et al. [92] reported that NF- $\mathrm{KB}$ signaling stimulated the differentiation of MDSCs into osteoclasts which then evoked bone erosion in collagen-induced mouse arthritis. Currently, the signaling pathways of NF- $\mathrm{KB}$ involved in the activation of MDSCs need to be clarified. It seems that the Toll-like receptor 4 (TLR4)/myeloid differentiation factor 88 (Myd88) signaling pathway is the major enhancer of the immunosuppressive activities of MDSCs and consequently induces immunosuppression, e.g., in conditions such as infections and cancers [93, 94]. Wang et al. [95] demonstrated that different TLR agonists specifically altered the differentiation and functions of human monocytic MDSCs. However, TLRs are linked not only to NF-kB signaling but some other pathways are also activated [96]. There is also cooperation with the NF-kB and STAT3 pathways linking inflammation to the development of several cancers [97]. For instance, the noncanonical NF-KB signaling pathway stimulated the STAT3-mediated expression of IDO in the MDSCs isolated from human breast cancer [74].

There is abundant literature indicating that the activation of AMPK inhibits NF-KB signaling via different mechanisms, e.g., by activating SIRT1, FoxO, p53, and PGC- $1 \alpha$ signaling pathways [6]. AMPK can also prevent the activation of NF- $K B$ signaling by inhibiting oxidative and endoplasmic reticulum (ER) stresses, well-known activators of NF- $\mathrm{kB}$ system. On the other hand, the activation of AMPK inhibited the TLR4/Myd88 pathway and attenuated immune responses [98, 99]. For instance, it was observed that AMPK activation reduced the expression of Myd88. Hong et al. [93] reported that 
the Myd $88^{-/-}$mice displayed a clear downregulation of the immunosuppressive properties in MDSCs. Recently, it was reported that AMPK activation regulates the functions of the NLRP3 subset of inflammasomes in both the aging process and tumorigenesis [100]. Inflammasomes are large multiprotein complexes which induce the maturation of the proforms of IL-1 $\beta$ (pro-IL-1 $\beta$ ) and IL-18 (pro-IL-18) and subsequently activate distinct inflammatory cascades. The NF-KB system and NLRP3 inflammasomes undergo crucial cooperation since the NF- $\mathrm{KB}$-dependent signaling induces the expression of NLRP3 as well as those of pro-IL- $1 \beta$ and proIL-18 [101]. Interestingly, in their studies conducted in transgenic $\mathrm{NLRP}^{-/-}$mice, van Deventer et al. [102] demonstrated that NLRP3 inflammasomes had a critical role in the functions of MDSC, e.g., they increased the accumulation of MDSCs into tumors and enhanced their immune suppressive properties. Recently, Chen et al. [103] reported that the pharmacological inhibition of NLRP3 inflammasomes suppressed the accumulation of MDSCs, Tregs, and TAMs into head and neck squamous cell carcinoma (HNSCC) in mice and consequently, the anti-cancer immunity of $\mathrm{CD} 4^{+}$and $\mathrm{CD} 8^{+} \mathrm{T}$ cells was improved. Many cellular stresses, e.g., ER and mitochondrial stresses, stimulate NF- $\mathrm{KB}$ signaling and activate NLRP3 inflammasomes, whereas the activation of AMPK enhances the maintenance of homeostasis, e.g., by activating autophagy and suppressing immune responses through the inhibition of NF-KB signaling $[6,100,104]$. This indicates that AMPK activators could be promising drugs for the future treatment of cancers and age-related degenerative diseases.

\section{C/EBPß factor}

The CCAAT/enhancer-binding protein $\beta(\mathrm{C} / \mathrm{EBP} \beta)$ is a versatile transcription factor which has important functions in cellular differentiation, e.g., monocytic lineage determination [105], as well as in the regulation of ER stress and metabolism [106]. Marigo et al. [107] demonstrated that the stimulation of the immunosuppressive properties of both mouse bone marrow-derived and the tumor-provoked MDSCs were dependent on the function of $\mathrm{C} / \mathrm{EBP} \beta$ factor. They also reported that the deletion of the $C e b p \beta$ gene from the cells of hematopoietic lineage decreased the numbers and tolerogenic activity of MDSCs in both the spleen and tumor sites of tumor-bearing mice. There was a significant decrease in the protein levels and activities of ARG1 and NOS2 in the MDSCs infiltrated into tumors of the $C e b p \beta$-deficient mice. Sepsis is another disease model in which $\mathrm{C} / \mathrm{EBP} \beta$ has a crucial role in the generation of immunosuppressive MDSCs in mouse bone marrow [108]. Dai et al. [108] demonstrated that the late phase of sepsis increased the expression of $\mathrm{C} / \mathrm{EBP} \beta$ protein which consequently induced the expression of miR-21 and miR $181 \mathrm{~b}$ in myeloid progenitors. This process stimulated the NF- $\mathrm{KB}$ signaling which enhanced myelopoiesis and expanded the population of immunosuppressive MDSCs. The conditional deletion of $C \operatorname{ebp} \beta$ in myeloid cells reversed the development of MDSCs during sepsis. McPeak et al. [109] reported that the myeloid-specific deficiency of $\mathrm{C} / \mathrm{EBP} \beta$ protein increased the maturation of mouse myeloid cells rather than promoting the accumulation of immature MDSCs during the late phase of sepsis, thus reducing sepsis mortality. Interestingly, the $\mathrm{C} / \mathrm{EBP} \beta$ factor stimulated the expression of immunosuppressive TGF- $\beta 1$ cytokine, whereas the TGF- $\beta 1$-activated Smad 3 and Smad4 factors repressed the transcriptional activity of $\mathrm{C} / \mathrm{EBP} \beta[110,111]$. These studies indicate that the regulation of $\mathrm{C} / \mathrm{EBP} \beta$ expression has a crucial role in the development and activity of MDSCs and thus it seems to be a promising drug target in many pathological conditions.

Given that adipogenesis is an anabolic process, it is known that AMPK signaling inhibits the differentiation of pre-adipocytes [112]. There is extensive evidence that the activators of AMPK can inhibit the expression and activity of $\mathrm{C} / \mathrm{EBP} \beta$, a major inducer of adipogenesis, in pre-adipocytes and thus suppress adipocyte differentiation $[113,114]$. It seems that AMPK signaling inhibits the $\mathrm{C} / \mathrm{EBP} \beta$ factor through indirect mechanisms. AMPK signaling represses the activity of $\mathrm{C} / \mathrm{EBP} \beta$ not only in adipocytes but it can also suppress diverse functions driven by $\mathrm{C} / \mathrm{EBP} \beta$, e.g., AMPK inhibits the $\mathrm{C} / \mathrm{EBP} \beta$-driven $\mathrm{ER}$ stress in hepatoma cells [115] and cardiomyocytes [116]. Matsuda et al. [117] demonstrated that ER stress in the mouse pancreatic islets induced the expression of $\mathrm{C} / \mathrm{EBP} \beta$ factor which consequently reduced the activity of AMPK, whereas the activation of AMPK suppressed the expression of $\mathrm{C} / \mathrm{EBP} \beta$ and alleviated ER stress. Lee et al. [118] reported that the ER stress, induced by thapsigargin, enhanced the immunosuppressive activity of MDSCs in tumor microenvironment. The expression of ARG1, iNOS, and NOX2 was significantly increased in tumor-infiltrated MDSCs. The administration of 4phenylbutyric acid (4-PBA), an ER stress-reducing chaperone, substantially decreased the immunosuppressive capacity of MDSCs and restored antitumor immunity.

\section{CHOP factor}

The C/EBP homologous protein (CHOP) is a transcription factor which is the main inducer of apoptosis in the conditions of ER stress [119]. Apoptosis is one of the mechanisms which regulate the number of MDSCs in inflamed tissues and thus control the level of immunosuppression in tissues. Chornoguz et al. [120] revealed that inflammatory conditions increased the resistance of MDSCs to apoptosis and thus enhanced their expansion in inflamed tissues. Thevenot et al. [121] demonstrated that MDSCs displayed the highest expression of CHOP in the sites of different mouse tumors as compared to other cell populations or even those of MDSCs in the spleen. 
The increased CHOP level in MDSCs correlated with their ability to inhibit $\mathrm{T}$ cell proliferation. The CHOP-deficient MDSCs displayed decreased immuno-regulatory functions, e.g., allowed the priming of $\mathrm{T}$ cell responses, enabled $\mathrm{T}$ cell proliferation, and delayed tumor growth. The exposure of ROS and peroxynitrite induced the expression of CHOP in mouse MDSCs, whereas antioxidants reduced its expression. Thevenot et al. [121] also reported that the expression of activating transcription factor 4 (ATF4), a key factor of integrated stress response (ISR), stimulated the expression of CHOP in MDSCs. Their results also indicated that the increased expression of CHOP activated the function of $\mathrm{C} / \mathrm{EBP} \beta / \mathrm{IL}-6$ axis which enhanced the immunosuppressive activity of MDSCs in inflamed tumor milieu. Recently, Shang et al. [122] revealed that mouse MDSCs expressed retinal non-coding RNA3 (RNCR3) which interacted with miR-185-5p, preventing its function. They demonstrated that miR-185-5p directly targeted the CHOP mRNA and thus blocked the translation of CHOP protein. The expression of RNCR3 in MDSCs was clearly increased in tumor microenvironment, probably stimulated by inflammatory cytokines. Shang et al. [122] also reported that the knockdown of RNCR3 in mice suppressed the differentiation and immunosuppressive properties of MDSCs which indicates that CHOP has an important role in the regulation of MDSC functions.

There is substantial evidence that the activation of AMPK can attenuate ER stress and protect tissues in diverse stress conditions $[123,124]$. There probably exist different mechanisms through which AMPK can alleviate the detrimental effects of ER stress. Dai et al. [125] isolated mouse macrophages and demonstrated that AMPK $\alpha 1$ phosphorylated CHOP protein at Ser30 inducing its ubiquitination and subsequently its degradation by proteasomes. The deletion of Ampk 1 gene significantly promoted the apoptosis of macrophages. These studies indicate that AMPK can prevent the overexpression of CHOP and thus counteract apoptotic cell death (Fig. 1). However, as revealed by Thevenot et al. [121] (above), the expression of CHOP was associated with an increased immunosuppressive capacity of MDSCs and thus it seems that MDSCs can evade apoptosis through the expression of survival factors induced by the ER stress-related activation of ATF4 [126].

\section{HIF-1a signaling}

Tumors established a hypoxic microenvironment which stimulates the expression of hypoxia-inducible factors (HIF) in both tumor cells and immune cells [127]. Hypoxia promotes the accumulation of immunosuppressive cells, e.g., MDSCs and Tregs, into tumors, thus allowing tumor cells an opportunity for immune escape. HIF-1 $\alpha$ signaling has crucial effects on both innate and adaptive immunity, e.g., HIF- $1 \alpha$ promotes the recruitment of Tregs into tumors, increases the differentiation of Th17 cells, and activates the functions of dendritic cells [127, 128]. Corzo et al. [129] observed that hypoxia in the tumor milieu increased the expression of ARG1 and iNOS in mouse MDSCs and interestingly, hypoxia induced the conversion of tumor-infiltrated MDSCs into TAMs. TAMs are immunosuppressive macrophages since they express a high level of ARG1, iNOS, IL-6, and IL-10 and inhibited the proliferation of T cells. Noman et al. [130] reported that HIF- $1 \alpha$, but not HIF- $2 \alpha$, increased the expression of membrane-bound programmed death receptor ligand 1 (PD-L1), an immune checkpoint receptor, which mediates the inhibition of T cells by binding to the PD-1 receptor of T cells. Recently, Li et al. [131] demonstrated that the TGF- $\beta$-mTORHIF- $1 \alpha$ signaling pathway induced the expression of CD39 and CD73 in human MDSCs. CD39 and CD73 are surface ectonucleotidases which hydrolyze extracellular ADP/ATP yielding adenosine. Ryzhov et al. [132] demonstrated that the adenosinergic regulation through the $\mathrm{A} 2 \mathrm{~B}$ receptors stimulated the proliferation and immunosuppressive activity of mouse granulocytic MDSCs. These studies indicate that hypoxia/HIF- $1 \alpha$ signaling is a potent inducer of immunosuppression by enhancing the expression of immune suppressive factors in MDSCs.

Although AMPK and HIF signaling pathways are evolutionarily conserved host defense mechanisms, it does seem that they have many mutually antagonistic activities in the regulation of energy metabolism and immune responses [133]. However, AMPK has a close connection with HIF- $1 \alpha$ signaling through several cooperative factors, e.g., sirtuin 1 (SIRT1), mammalian target of rapamycin (mTOR), and $\mathrm{NF}-\mathrm{KB}$ signaling pathways which either activate or inhibit the function of HIF- $1 \alpha$. It has been recognized that the activation of AMPK stimulates the signaling of SIRT1, whereas it inhibits the functions of mTOR and NF-KB $[6,14,16]$. It is known that all these factors are able to enhance the function of HIF-1 $\alpha$ via several mechanisms [134-136]. In addition, Chen et al. [137] demonstrated that AMPK regulated the nuclear localization of HIF- $1 \alpha$ via the control of cytosolic shuttling of histone deacetylase 5 (HDAC5). It seems that the activation of AMPK can also inhibit the expression of immunosuppressive proteins induced by HIF-1 $\alpha$, e.g., CD39/CD73 and PDL1. Li et al. [138] demonstrated that the metformin-induced AMPK activation reduced the expression of CD39 and CD73 in the MDSCs of ovarian cancer patients and consequently attenuated the immunosuppressive activity of MDSCs. Recently, Cha et al. [139] revealed that the metforminactivated AMPK directly phosphorylated PD-L1 protein at S195 which induced the abnormal glycosylation of PD-L1 and its subsequent degradation through the ER-associated protein proteasomal degradation (ERAD). These observations indicate that AMPK signaling can either enhance or suppress the HIF- $1 \alpha$-induced functions of MDSCs in a contextdependent manner (Fig. 1). 


\section{NFE2L2/NRF2 signaling}

Nuclear factor (erythroid derived 2) like (NFE2L2/NRF2) has not only a crucial role in the protection against oxidative stress but it also regulates innate immunity, e.g., through the inhibition of NF- $\mathrm{kB}$ signaling [140]. Since it is known that NFE2L2 is a powerful survival factor, it is not surprising that the activation of AMPK signaling stimulates the function of NFE2L2 pathway [141, 142] (Fig. 1). Joo et al. [142] observed that AMPK activation increased the accumulation of NFE2L2 transcription factors into the nuclei of HepG2 cells. They demonstrated that AMPK phosphorylated the Ser558 residue (Ser550 in mouse) in the human NFE2L2 protein. The mutation of these serine residues inhibited the accumulation of NFE2L2 into nuclei after AMPK activation. Because the Ser550/Ser558 residues are located in the nuclear export signal of NFE2L2 protein, it was proposed that the AMPKinduced phosphorylation prevented the export of NFE2L2 from the nuclei, thus enhancing the NFE2L2-mediated transcription. Beury et al. [143] compared the properties of MDSCs isolated from the NFE2L2 ${ }^{+/+}$mice and the transgenic NFE2L2 $2^{-1-}$ mice. They reported that the MDSCs isolated from the NFE2L2 $2^{+/+}$mice suppressed more efficiently the function of $\mathrm{CD}^{+}$and $\mathrm{CD} 8^{+} \mathrm{T}$ cells than the MDSCs from the NFE2L2 $2^{-/-}$mice. In addition, to increased immune suppressive activity, the numbers of MDSCs in tumors were significantly higher in mice with NFE2L $2^{+/+}$in comparison with their counterparts deficient of NFE2L2. They also observed that the level of ROS compounds was significantly lower in the MDSCs with NFE2L2 $2^{+/+}$than in those lacking NFE2L2. This difference prevented the apoptosis of MDSCs since the tumor microenvironment is characterized by oxidative stress. Recently, Ohl et al. [144] revealed that the constitutive activation of NFE2L2 in mice induced the accumulation of MDSCs into the spleen. Moreover, the permanent increase in NFE2L2 activity enhanced the immune suppressive properties of MDSCs, e.g., mediated protection against LPS-induced sepsis. It seems that AMPK signaling activates the NFE2L2 pathway to facilitate the survival of MDSCs in diverse stresses, e.g., oxidative stress in inflammatory conditions (Fig. 1).

\section{AMPK controls MDSC activity via metabolic regulation}

Currently, it has been recognized that energy metabolism is an important regulator of immune responses; the term immunometabolism has been coined to describe this process [145]. For instance, metabolic regulation has a crucial role in the functions of myeloid-derived immune cells in cancer and chronic inflammatory diseases [146, 147]. The Warburg effect, i.e., the aerobic glycolytic process producing lactate from glucose, is a well-characterized hallmark of cancer cells [148]. However, the Warburg effect does not only occur in tumors but recent studies have also revealed that immune cells in inflammatory diseases undertake energy production through aerobic glycolysis [149-151]. The activation of the myeloid cells, e.g., neutrophils, dendritic cells, and macrophages, stimulates aerobic glycolysis and thus triggers lactate production in inflamed tissues. Moreover, Menk et al. [152] demonstrated that the activation of the T cell receptor (TCR) induced the activation of pyruvate dehydrogenase kinase 1 (PDHK1) which inhibited pyruvate import into the mitochondria, thus facilitating its processing into lactate in the cytoplasm. Aerobic glycolysis has an important role in the shaping of $\mathrm{T}$ cell differentiation [153]. Lactate is not only a metabolite but it also possesses many signaling properties [154] and furthermore, it is a potent inducer of immunosuppression in inflammatory conditions, e.g., in sepsis [155]. For instance, in murine tumor models, the myeloid-specific knockout of lactate dehydrogenase-A (LDH-A) [156] or the reduction of lactate production by diclofenac exposure [157] reduced the T cell immunosuppression and increased antitumor immunity. Interestingly, Husain et al. [158] demonstrated that the addition of lactate to MDSC cultures significantly increased the expansion of immunosuppressive MDSCs which reduced the proliferation of $\mathrm{CD}^{+} \mathrm{T}$ cells and inhibited the cytotoxicity of $\mathrm{CD}^{+} \mathrm{T}$ cells and natural killer (NK) cells. Recently, Cai et al. [159] observed that the Epstein-Barr virus (EBV) promoted the proliferation of MDSCs in human nasopharyngeal carcinoma by increasing aerobic glycolysis and lactate production in cancer cells. The lactate shuttling between cells increases in the microenvironments of tumors and inflamed tissues [160] and it is possible that lactate acts as the inducer of expansion and activation of MDSCs in tissues and thus can augment tissue immunosuppression (Fig. 2).

Given that AMPK is a crucial metabolic regulator, it seems likely that AMPK can also control the functions of MDSCs through metabolic regulation. Interestingly, some transcription factors inhibited by AMPK signaling are potent enhancers of glycolysis, especially of the Warburg effect in immune cells (Fig. 2). It is known that STAT3 and NF-KB signaling pathways, suppressed by AMPK activation (Fig. 1), can stimulate HIF- $1 \alpha$ signaling which is a major inducer of aerobic glycolysis and lactate production $[149,161]$. However, AMPK signaling is also able to enhance the activity of HIF-1 $\alpha$, e.g., NFE2L2/NRF2 induces the metabolic shift to aerobic glycolysis via HIF-1 $\alpha$ signaling [162]. Mammalian target of rapamycin (mTOR), inhibited by AMPK activation, is an effective activator of HIF- $1 \alpha$ signaling and thus can trigger lactate production [134] (Fig. 2).

There is abundant evidence that mTOR is an important regulator of the differentiation and immunosuppressive functions of MDSCs [163-165]. Deng et al. [165] demonstrated that the mTOR-induced glycolysis enhanced the immune suppressive properties of tumor-infiltrated monocytic MDSCs in mice. In contrast, rapamycin treatment reduced the level of glycolysis and decreased the suppressive activities of 
MDSCs. Chen et al. [164] revealed that the isolated hepatic MDSCs from the mice with the Con A-induced immune-mediated hepatic injury $(\mathrm{CIH})$ displayed an increased glycolytic activity along with increased expression of glycolytic enzymes, e.g., LDH-A. It was observed that rapamycin decreased the glycolytic activity in the hepatic MDSCs of CIH mice. Similar results were observed after the exposure of 2deoxy-D-glucose (2-DG), a competitive inhibitor of glucose6-phosphatase. The mTOR signaling in hepatic MDSCs controlled the HIF- $1 \alpha$-dependent glycolytic activity and suppressed T cell activation. Furthermore, Makki et al. [163] reported that the exposure of obese mice to rapamycin increased the total number of granulocytic MDSCs whereas that of monocytic MDSCs was decreased in both the blood and adipose tissue. It seems that metabolic regulation can differently affect the two subtypes of MDSCs as well as controlling the polarization of MDSCs between the pro-inflammatory M1 and immunosuppressive M2 phenotypes. For instance, it is known that sirtuin 1 (SIRT1), the cooperating partner of AMPK, regulates the M1/M2 switch of MDSCs through the mTOR-HIF- $1 \alpha$ pathway [166]. These studies indicate that there is a complex regulatory network behind the glycolytic reprogramming of the suppressive properties of MDSCs.

Aerobic glycolysis is not the only source of lactate since glutaminolysis, i.e., the catabolism of L-glutamine can generate lactate in mouse MDSCs [167] (Fig. 2). In particular, the use of L-glutamine is an important carbon source in the maturation of MDSCs. It is known that glutaminolysis is a crucial compensatory energy pathway in conditions where the supply of pyruvate into mitochondria is compromised [168]. Recently, Morikawa et al. [169] demonstrated that the metabotropic glutamate receptor $2 / 3$ (mGluR2/3) was expressed in mouse MDSCs and it played an important role in the maintenance of immunosuppressive properties of MDSCs. For instance, cancer cells secrete glutamate which can be processed in cells through glutaminolysis. Overall, it seems that the metabolic regulation of MDSC functions is controlled by the energy metabolic processes in both MDSCs and their neighboring cells.

Fatty acids are not only the source of energy production through $\beta$-oxidation but they have diverse functions in the regulation of immune system $[170,171]$. For instance, there is substantial evidence that the dietary supplementation of polyunsaturated fatty acids (PUFA), i.e., omega-3 ( $\omega-3)$ and omega-6 ( $\omega-6)$ fatty acids, have immunosuppressive responses, e.g., to the signal transduction and antigen presentation of human T cells $[172,173]$. Moreover, $\omega-3$ and $\omega-6$ fatty acids are the precursors of prostaglandin synthesis via cyclooxygenases $(\mathrm{COX})$ and it is known that prostaglandin E2 (PGE2) exerted profound effects on immune cells [174]. Interestingly, Yan et al. [72] demonstrated that both the $\omega-3$ and $\omega-6$ PUFA treatments significantly enhanced the expansion of cultured bone marrow MDSCs, especially that of granulocytic MDSCs. The proliferation of T cells decreased in a dose-dependent manner of PUFAs. The exposure of mice with PUFAs increased the percentage of granulocytic MDSCs in both the bone marrow and the spleen. The administration of PUFA also stimulated the immunosuppressive properties of MDSCs isolated from mouse spleen. The PUFA treatment induced the activation of JAK-STAT3 signaling (Fig. 2) and the immunosuppression of $\mathrm{T}$ cells was mediated by ROS. Finally, Yan et al. [72] revealed that a PUFA-enriched diet augmented the growth of CT26 and Lewis lung carcinoma in mice. In agreement with these results, Xia et al. [175] reported that provision of a $\omega-3$ enriched fish oil diet promoted the expansion of MDSCs in the mouse spleen. Correspondingly, this diet suppressed the cytotoxicity of $\mathrm{CD} 8^{+} \mathrm{T}$ cells and increased the growth of melanoma. Given that PUFAs activate PGE2 production through COX-2 (above), it is interesting that PGE2 can stimulate STAT3 signaling [176]. It is known that PGE2 is a potent inducer of the functions of MDSCs [177] and thus might stimulate the expansion of MDSCs. Remarkably, it seems that AMPK signaling can suppress the PUFA-induced expansion of MDSCs since it is known that in addition to the JAK-STAT3 signaling, AMPK activation can also inhibit the COX-2 signaling [178]. Moreover, the inhibition of COX-2 enzyme by celecoxib administration reduced the level of PGE2 and prevented the expansion of both MDSC subtypes in tumor-bearing mice [179]. These studies indicate that AMPK signaling is a potent inhibitor of the PUFA-induced activation of MDSCs (Fig. 2).

Obesity is associated with chronic inflammation in adipose tissues and thus it is not surprising that MDSCs accumulate into adipose tissues during obesity [180]. It is known that the fatty acid oxidation (FAO) of MDSCs increases in the tumor microenvironment [181, 182]. Hossain et al. [181] demonstrated that the inhibition of FAO after exposure to etomoxir or ranolazine reduced the immunosuppressive properties of MDSCs, e.g., the expression of ARG1 and several cytokines as well as their ability to inhibit $\mathrm{T}$ cell proliferation. The inhibition of FAO also suppressed the growth of carcinomas in mice. In addition, they reported that the capacity of fatty acid uptake and oxidation was significantly increased in the circulating and tumor-infiltrated MDSCs in cancer patients. The mechanisms underpinning the FAO-induced activation of MDSCs still need to be clarified (Fig. 2). However, AlKhami et al. [182] demonstrated that the tumor-derived factors, e.g., GM-CSF and IL-6, stimulated lipid uptake and metabolism in tumor-infiltrated MDSCs. An increase in lipid oxidation enhanced the immunosuppressive properties of MDSCs through the activation of STAT3 signaling in the tumor microenvironment. They also observed that the deletion of CD36, a fatty acid translocase, decreased the immunosuppressive properties of MDSCs and inhibited tumor growth in CD36 knockout mice. Interestingly, it has been reported that CD36 protein inhibits the activation of AMPK but the binding 
of fatty acid to the CD36 receptor activates AMPK signaling which consequently stimulates the $\beta$-oxidation of fatty acids [183] (Fig. 2). One might speculate that the activation of CD36 by fatty acids stimulates AMPK signaling which enhances energy production through FAO while at the same time, it might control the immunosuppressive functions of MDSCs via an inhibition of major inducers of MDSCs (Fig. 1).

\section{AMPK-mediated control of MDSCs in cancer therapy and longevity regulation}

There is substantial evidence that AMPK signaling regulates cancer growth although many studies have revealed that AMPK activation can induce either an oncogenic or a tumor suppressive process in a context-dependent manner [5]. It seems that AMPK signaling can act as a tumor suppressor by inhibiting the function of major transcription factors associated with tumorigenesis in several ways, e.g., (i) AMPK inhibits the AKT/mTOR-dependent cancer growth [184], (ii) AMPK inhibits the JAK-STAT signaling which enhances tumorigenesis [185], (iii) AMPK inhibits the NF- $\mathrm{KB}$ system linked to the inflammation-mediated tumorigenesis [90], and (iv) AMPK inhibits $\mathrm{C} / \mathrm{EBP} \beta$ signaling which affects metastasis [186]. AMPK activation can also context-dependently inhibit HIF- $1 \alpha$ signaling which is a crucial inducer of carcinogenesis [187]. Interestingly, all of these pathways are important enhancers of MDSC expansion and activation in inflamed microenvironment suggesting that the activators of AMPK might be important drugs in cancer therapy. Currently, there is clear evidence that metformin, an AMPK activator, is a promising drug candidate for cancer therapy although metformin also has AMPK-independent targets [188]. Uehara et al. [69] demonstrated that metformin administration inhibited the growth of osteosarcoma in mice. They observed that metformin treatment reduced the numbers of granulocytic MDSCs in both the spleen and tumors. Metformin treatment increased the ROS production of isolated MDSCs and redirected their energy metabolism from oxidative phosphorylation to glycolysis. In addition, many flavonoids and terpenoids might mediate the inhibition of MDSCs through the activation of AMPK signaling [53]. There are several possible mechanisms to explain how the activators of AMPK could suppress the functions of MDSCs in cancer therapy. For instance, it is known that AMPK activators downregulate the chemokine signaling in macrophages $[189,190]$ which might impair the chemokine-driven accumulation of MDSCs into tumors. Given that AMPK activators have displayed beneficial effects in cancer combination therapies [191], it would be important to clarify whether they could improve cancer immunotherapies by inhibiting the MDSC-induced immunosuppression.

AMPK signaling has a crucial role in the regulation of longevity since it controls several signaling pathways associated with the aging process $[16,17]$. For instance, AMPK activation inhibits the NF- $\mathrm{KB}$ and mTORmediated signaling, two pathways known to accelerate the aging process. In contrast, AMPK signaling stimulates SIRT1, FoxO/DAF-16, and NFE2L2/NRF2 pathways which enhance stress resistance and can increase longevity. In addition, the signaling of two pro-longevity factors, i.e., caloric restriction [192] and fibroblast growth factor 21 (FGF21) [193], stimulate AMPK signaling and thus could affect the regulation of MDSCs. Currently, there is no direct evidence on the role of caloric restriction and FGF21 in the activation or expansion of MDSCs. However, metformin is a promising tool to delay the aging process [194] and it inhibits the expansion of MDSCs [69]. As described above, the presence of MDSCs significantly increases with aging, probably induced by the chronic inflammaging condition in tissues. It seems that AMPK signaling can influence the appearance and activity of MDSCs in a multifaceted manner. For instance, AMPK activation prevents inflammatory responses by inhibiting the NF- $\mathrm{kB}$ signaling system and thus it downregulates the generation of chemotactic factors in inflamed tissues which consequently eliminates the generation of MDSCs in the bone marrow. In addition, it is known that the activation of mTOR, a well-known longevity suppressor, stimulates the expression of G-CSF which increases the expansion and infiltration of MDSCs into tumors [195]. AMPK signaling can also directly control the differentiation of myeloid cells [196] which might affect the generation of MDSCs with aging. On the other hand, AMPK signaling can suppress the major signaling pathways which stimulate the immunosuppressive properties of MDSCs (Fig. 1) and thus it could exert a local control of the functions of MDSCs. Given that AMPK signaling promotes catabolic activities rather than anabolic processes, it is likely that AMPK activation suppresses energyconsuming translational processes and thus inhibits the proliferation of MDSCs. Currently, the role of MDSC expansion associated with inflammaging needs to be clarified although it seems that the age-related immunosenescence could be induced by the activation of immunosuppressive network involving MDSCs, Tregs, and regulatory M2 macrophages [11]. Immunosuppressive cells secrete antiinflammatory cytokines, e.g., TGF- $\beta$ and IL-10, which have degenerative bystander effects in inflamed tissues [10]. Moreover, the increased expression of ARG1 and IDO induces a shortage of amino acids disturbing the maintenance of proteostasis in aged tissues. The age-related expansion of MDSCs could also increase the prevalence of tumors and chronic infections and reduce the efficacy of cancer immunotherapies. It seems that the activators of AMPK signaling are potent inhibitors of MDSC functions and subsequently, they might mitigate the effects of inflammaging and thus extend healthspan and lifespan. 


\section{Conclusions}

AMPK signaling has several functions beyond the regulation of energy metabolism. For instance, AMPK signaling regulates many activities of innate and adaptive immunity by targeting the major immune signaling pathways which control the differentiation and activity of immune cells. Moreover, AMPK signaling regulates the energy metabolism of immune cells and these immunometabolic processes have a crucial role in the control of activity of immune cells. It seems that AMPK activation regulates the functions of MDSCs in a context-dependent manner. Given that MDSCs have a key role in the maintenance of immunosuppression in conditions of chronic inflammation, the AMPKinduced suppression of MDSC expansion and activation might increase the efficiency of the immune system, e.g., in tumors and chronic infections, and thus alleviate chronic inflammation. In addition, AMPK activation might also mitigate age-related immune deficiency and thus improve healthspan. AMPK signaling also controls the energy metabolism of MDSCs by enhancing the fatty acid oxidation which increases the immunosuppressive potentials of MDSCs. Metabolites can also control the activity of MDSCs since lactate stimulates the immunosuppressive properties of MDSCs. Lactate could be an important inducer of the functions of MDSCs during acute inflammation and thus enhance the resolution of inflammation. It is known that immune cells switch on aerobic glycolysis during acute inflammation. Moreover, tumor cells display increased aerobic glycolysis associated with the production of lactate which might be an important enhancer of the expansion and activation of MDSCs in tumor sites.

Acknowledgements Open access funding provided by University of Eastern Finland (UEF) including Kuopio University Hospital. The authors thank Dr. Ewen MacDonald for checking the language of the manuscript.

Funding information This study was financially supported by grants from the Academy of Finland (AK297267, AK307341, and KK296840), the Kuopio University Hospital VTR grant (KK5503743), the Emil Aaltonen Foundation, the Sigrid Juselius Foundation, the Päivikki and Sakari Sohlberg Foundation, the Finnish Cultural Foundation, and the Finnish Eye Foundation.

\section{Compliance with ethical standards}

Conflict of interest The authors declare that they have no conflict of interest.

Open Access This article is distributed under the terms of the Creative Commons Attribution 4.0 International License (http:// creativecommons.org/licenses/by/4.0/), which permits unrestricted use, distribution, and reproduction in any medium, provided you give appropriate credit to the original author(s) and the source, provide a link to the Creative Commons license, and indicate if changes were made.

\section{References}

1. O’Neill LA, Hardie DG (2013) Metabolism of inflammation limited by AMPK and pseudo-starvation. Nature 493:346-355

2. Blagih J, Coulombe F, Vincent EE, Dupuy F, Galicia-Vazquez G, Yurchenko E, Raissi TC, van der Windt GJ, Viollet B, Pearce EL, Pelletier J, Piccirillo CA, Krawczyk CM, Divangahi M, Jones RG (2015) The energy sensor AMPK regulates T cell metabolic adaptation and effector responses in vivo. Immunity 42:41-54

3. Hardie DG (2014) AMP-activated protein kinase: a key regulator of energy balance with many roles in human disease. J Intern Med 276:543-559

4. Jeon SM (2016) Regulation and function of AMPK in physiology and diseases. Exp Mol Med 48:e245

5. Zadra G, Batista JL, Loda M (2015) Dissecting the dual role of AMPK in cancer: from experimental to human studies. Mol Cancer Res 13:1059-1072

6. Salminen A, Hyttinen JM, Kaarniranta K (2011) AMP-activated protein kinase inhibits NF- $\mathrm{kB}$ signaling and inflammation: impact on healthspan and lifespan. J Mol Med (Berl) 89:667-676

7. Rutherford C, Speirs C, Williams JJ, Ewart MA, Mancini SJ, Hawley SA, Delles C, Viollet B, Costa-Pereira AP, Baillie GS, Salt IP, Palmer TM (2016) Phosphorylation of Janus kinase 1 (JAK1) by AMP-activated protein kinase (AMPK) links energy sensing to anti-inflammatory signaling. Sci Signal 9:ra109

8. Gabrilovich DI, Nagaraj S (2009) Myeloid-derived suppressor cells as regulators of the immune system. Nat Rev Immunol 9: 162-174

9. Millrud CR, Bergenfelz C, Leandersson K (2017) On the origin of myeloid-derived suppressor cells. Oncotarget 8:3649-3665

10. Salminen A, Kaarniranta K, Kauppinen A (2018) The role of myeloid-derived suppressor cells (MDSC) in the inflammaging process. Ageing Res Rev 48:1-10

11. Salminen A, Kaarniranta K, Kauppinen A (2019) Immunosenescence: the potential role of myeloid-derived suppressor cells (MDSC) in age-related immune deficiency. Cell Mol Life Sci 76:1901-1918

12. Hardie DG (2014) AMPK - sensing energy while talking to other signaling pathways. Cell Metab 20:939-952

13. Hardie DG, Schaffer BE, Brunet A (2016) AMPK: an energy-sensing pathway with multiple inputs and outputs. Trends Cell Biol 26:190201

14. Mihaylova MM, Shaw RJ (2011) The AMPK signalling pathway coordinates cell growth, autophagy and metabolism. Nat Cell Biol 13:1016-1023

15. Hardie DG (2015) Molecular pathways: is AMPK a friend or a foe in cancer? Clin Cancer Res 21:3836-3840

16. Salminen A, Kaarniranta K (2012) AMP-activated protein kinase (AMPK) controls the aging process via an integrated signaling network. Ageing Res Rev 11:230-241

17. Burkewitz K, Zhang Y, Mair WB (2014) AMPK at the nexus of energetics and aging. Cell Metab 20:10-25

18. Sag D, Carling D, Stout RD, Suttles J (2008) Adenosine 5'monophosphate-activated protein kinase promotes macrophage polarization to an anti-inflammatory functional phenotype. J Immunol 181:8633-8641

19. Zhu YP, Brown JR, Sag D, Zhang L, Suttles J (2015) Adenosine 5 '-monophosphate-activated protein kinase regulates IL-10mediated anti-inflammatory signaling pathways in macrophages. J Immunol 194:584-594

20. Ishii N, Matsumura T, Kinoshita H, Motoshima H, Kojima K, Tsutsumi A, Kawasaki S, Yano M, Senokuchi T, Asano T, Nishikawa T, Araki E (2009) Activation of AMP-activated protein kinase suppresses oxidized low-density lipoprotein-induced macrophage proliferation. J Biol Chem 284:34561-34569 
21. Morales JK, Kmieciak M, Knutson KL, Bear HD, Manjili MH (2010) GM-CSF is one of the main breast tumor-derived soluble factors involved in the differentiation of $\mathrm{CD} 1 \mathrm{~b}^{-} \mathrm{Gr}^{-}$bone marrow progenitor cells into myeloid-derived suppressor cells. Breast Cancer Res Treat 123:39-49

22. Andris F, Leo O (2015) AMPK in lymphocyte metabolism and function. Int Rev Immunol 34:67-81

23. Waight JD, Netherby C, Hensen ML, Miller A, Hu Q, Liu S, Bogner PN, Farren MR, Lee KP, Liu K, Abrams SI (2013) Myeloid-derived suppressor cell development is regulated by a STAT/IRF-8 axis. J Clin Invest 123:4464-4478

24. Ko HJ, Kim YJ (2016) Signal transducer and activator of transcription proteins: regulators of myeloid-derived suppressor cell-mediated immunosuppression in cancer. Arch Pharm Res 39:1597-1608

25. Zhao Y, Wu T, Shao S, Shi B, Zhao Y (2015) Phenotype, development, and biological function of myeloid-derived suppressor cells. Oncoimmunology 5:e1004983

26. Salminen A, Kauppinen A, Kaarniranta K (2018) Myeloidderived suppressor cells (MDSC): an important partner in cellular/tissue senescence. Biogerontology 19:325-339

27. Motallebnezhad M, Jadidi-Niaragh F, Qamsari ES, Bagheri S, Gharibi T, Yousefi M (2016) The immunobiology of myeloidderived suppressor cells in cancer. Tumour Biol 37:1387-1406

28. Veglia F, Perego M, Gabrilovich D (2018) Myeloid-derived suppressor cells coming of age. Nat Immunol 19:108-119

29. Safari E, Ghorghanlu S, Ahmadi-Khiavi H, Mehranfar S, Rezaei R, Motallebnezhad M (2018) Myeloid-derived suppressor cells and tumor: current knowledge and future perspectives. J Cell Physiol 234:9966-9981

30. Ohl K, Tenbrock K (2018) Reactive oxygen species as regulators of MDSC-mediated immune suppression. Front Immunol 9:2499

31. Li MO, Wan YY, Sanjabi S, Robertson AK, Flavell RA (2006) Transforming growth factor- $\beta$ regulation of immune responses. Annu Rev Immunol 24:99-146

32. Park MJ, Lee SH, Kim EK, Lee EJ, Park SH, Kwok SK, Cho ML (2016) Myeloid-derived suppressor cells induce the expansion of regulatory B cells and ameliorate autoimmunity in the Sanroque mouse model of systemic lupus erythematosus. Arthritis Rheum 68:27172727

33. Moore KW, de Waal Malefyt R, Coffman RL, O'Garra A (2001) Interleukin-10 and the interleukin-10 receptor. Annu Rev Immunol 19:683-765

34. Corzo CA, Cotter MJ, Cheng P, Cheng F, Kusmartsev S, Sotomayor E, Padhya T, McCaffrey TV, McCaffrey JC, Gabrilovich DI (2009) Mechanism regulating reactive oxygen species in tumor-induced myeloid-derived suppressor cells. J Immunol 182:5693-5701

35. Nagaraj S, Gupta K, Pisarev V, Kinarsky L, Sherman S, Kang L, Herber DL, Schneck J, Gabrilovich DI (2007) Altered recognition of antigen is a mechanism of $\mathrm{CD} 8^{+} \mathrm{T}$ cell tolerance in cancer. Nat Med 13:828-835

36. Mondanelli G, Ugel S, Grohmann U, Bronte V (2017) The immune regulation in cancer by the amino acid metabolizing enzymes ARG and IDO. Curr Opin Pharmacol 35:30-39

37. Lei GS, Zhang C, Lee CH (2015) Myeloid-derived suppressor cells impair alveolar macrophages through PD-1 receptor ligation during Pneumocystis pneumonia. Infect Immun 83:572-582

38. Lu C, Redd PS, Lee JR, Savage N, Liu K (2016) The expression profiles and regulation of PD-L1 in tumor-induced myeloid-derived suppressor cells. Oncoimmunology 5:e1247135

39. Xu-Monette ZY, Zhang M, Li J, Young KH (2017) PD-1/PD-L1 blockade: have we found the key to unleash the antitumor immune response? Front Immunol 8:1597

40. Cuenca AG, Delano MJ, Kelly-Scumpia KM, Moreno C, Scumpia PO, Laface DM, Heyworth PG, Efron PA, Moldawer
LL (2011) A paradoxical role for myeloid-derived suppressor cells in sepsis and trauma. Mol Med 17:281-292

41. Dorhoi A, Du Plessis N (2018) Monocytic myeloid-derived suppressor cells in chronic infections. Front Immunol 8:1895

42. Saiwai H, Kumamaru H, Ohkawa Y, Kubota K, Kobayakawa K, Yamada H, Yokomizo T, Iwamoto Y, Okada S (2013) Ly6C ${ }^{+}$ Ly6 $\mathrm{G}^{-}$myeloid-derived suppressor cells play a critical role in the resolution of acute inflammation and the subsequent tissue repair process after spinal cord injury. J Neurochem 125:74-88

43. Hotchkiss RS, Monneret G, Payen D (2013) Sepsis-induced immunosuppression: from cellular dysfunctions to immunotherapy. Nat Rev Immunol 13:862-874

44. Shi K, Wood K, Shi FD, Wang X, Liu Q (2018) Stroke-induced immunosuppression and poststroke infection. Stroke Vasc Neurol 3:34-41

45. Vallejo AN (2007) Immune remodeling: lessons from repertoire alterations during chronological aging and in immune-mediated disease. Trends Mol Med 13:94-102

46. Talmadge JE, Gabrilovich DI (2013) History of myeloid-derived suppressor cells. Nat Rev Cancer 13:739-752

47. Bunt SK, Yang L, Sinha P, Clements VK, Leips J, OstrandRosenberg S (2007) Reduced inflammation in the tumor microenvironment delays the accumulation of myeloid-derived suppressor cells and limits tumor progression. Cancer Res 67:1001910026

48. Umansky V, Blattner C, Fleming V, Hu X, Gebhardt C, Altevogt P, Utikal J (2017) Myeloid-derived suppressor cells and tumor escape from immune surveillance. Semin Immunopathol 39:295305

49. Draghiciu O, Lubbers J, Nijman HW, Daemen T (2015) Myeloid derived suppressor cells - an overview of combat strategies to increase immunotherapy efficacy. Oncoimmunology 4:e954829

50. Shipp C, Speigl L, Janssen N, Martens A, Pawelec G (2016) A clinical and biological perspective of human myeloid-derived suppressor cells in cancer. Cell Mol Life Sci 73:4043-4061

51. Xin H, Zhang C, Herrmann A, Du Y, Figlin R, Yu H (2009) Sunitinib inhibition of Stat3 induces renal cell carcinoma tumor cell apoptosis and reduces immunosuppressive cells. Cancer Res 69:2506-2513

52. Yuan H, Cai P, Li Q, Wang W, Sun Y, Xu Q, Gu Y (2014) Axitinib augments antitumor activity in renal cell carcinoma via STAT3dependent reversal of myeloid-derived suppressor cell accumulation. Biomed Pharmacother 68:751-756

53. Salminen A, Kaarniranta K, Kauppinen A (2018) Phytochemicals inhibit the immunosuppressive functions of myeloid-derived suppressor cells (MDSC): impact on cancer and age-related chronic inflammatory disorders. Int Immunopharmacol 61:231-240

54. Nefedova Y, Fishman M, Sherman S, Wang X, Beg AA, Gabrilovich DI (2007) Mechanism of all-trans retinoic acid effect on tumor-associated myeloid-derived suppressor cells. Cancer Res 67:11021-11028

55. Tian J, Ma J, Ma K, Guo H, Baidoo SE, Zhang Y, Yan J, Lu L, Xu H, Wang S (2013) $\beta$-Glucan enhances antitumor immune responses by regulating differentiation and function of monocytic myeloid-derived suppressor cells. Eur J Immunol 43:1220-1230

56. Franceschi $\mathrm{C}$, Valensin $\mathrm{S}$, Bonafè $\mathrm{M}$, Paolisso $\mathrm{G}$, Yashin AI, Monti D, De Benedictis G (2000) The network and the remodeling theories of aging: historical background and new perspectives. Exp Gerontol 35:879-896

57. Franceschi C, Capri M, Monti D, Giunta S, Olivieri F, Sevini F, Panourgia MP, Invidia L, Celani L, Scurti M, Cevenini E, Castellani GC, Salvioli S (2007) Inflammaging and antiinflammaging: a systemic perspective on aging and longevity emerged from studies in humans. Mech Ageing Dev 128:92-105 
58. Frasca D, Blomberg BB (2016) Inflammaging decreases adaptive and innate immune responses in mice and humans. Biogerontology 17:7-19

59. Verschoor CP, Johnstone J, Millar J, Dorrington MG, Habibagahi M, Lelic A, Loeb M, Bramson JL, Bowdish DM (2013) Blood $\mathrm{CD}^{+} 3^{+} \mathrm{HLA}^{-} \mathrm{DR}^{-}$myeloid-derived suppressor cells are increased with age and a history of cancer. J Leukoc Biol 93:633-637

60. Alves AS, Ishimura ME, Duarte YAO, Bueno V (2018) Parameters of the immune system and vitamin D levels in old individuals. Front Immunol 9:1122

61. Enioutina EY, Bareyan D, Daynes RA (2011) A role for immature myeloid cells in immune senescence. J Immunol 186:697-707

62. Jackaman C, Radley-Crabb HG, Soffe Z, Shavlakadze T, Grounds MD, Nelson DJ (2013) Targeting macrophages rescues agerelated immune deficiencies in C57BL/6J geriatric mice. Aging Cell 12:345-357

63. Flores RR, Clauson CL, Cho J, Lee BC, McGowan SJ, Baker DJ, Niedernhofer LJ, Robbins PD (2017) Expansion of myeloidderived suppressor cells with aging in the bone marrow of mice through a NF-kB-dependent mechanism. Aging Cell 16:480-487

64. Kovtonyuk LV, Fritsch K, Feng X, Manz MG, Takizawa H (2016) Inflamm-aging of hematopoiesis, hematopoietic stem cells, and the bone marrow microenvironment. Front Immunol 7:502

65. Pang WW, Price EA, Sahoo D, Beerman I, Maloney WJ, Rossi DJ, Schrier SL, Weissman IL (2011) Human bone marrow hematopoietic stem cells are increased in frequency and myeloid-biased with age. Proc Natl Acad Sci U S A 108:20012-20017

66. Challen GA, Boles NC, Chambers SM, Goodell MA (2010) Distinct hematopoietic stem cell subtypes are differentially regulated by TGF- $\beta 1$. Cell Stem Cell 6:265-278

67. Trikha P, Plews RL, Stiff A, Gautam S, Hsu V, Abood D, Wesolowski R, Landi I, Mo X, Phay J, Chen CS, Byrd J, Caligiuri M, Tridandapani S, Carson W (2016) Targeting myeloid-derived suppressor cells using a novel adenosine monophosphate-activated protein kinase (AMPK) activator. Oncoimmunology 5:e1214787

68. Qin G, Lian J, Huang L, Zhao Q, Liu S, Zhang Z, Chen X, Yue D, Li L, Li F, Wang L, Umansky V, Zhang B, Yang S, Zhang Y (2018) Metformin blocks myeloid-derived suppressor cell accumulation through AMPK-DACH1-CXCL1 axis. Oncoimmunology 7:e1442167

69. Uehara T, Eikawa S, Nishida M, Kunisada Y, Yoshida A, Fujiwara T, Kunisada T, Ozaki T, Udono H (2018) Metformin induces $\mathrm{CD} 11 \mathrm{~b}+$ cell-mediated growth inhibition of an osteosarcoma: implications for metabolic reprogramming of myeloid cells and antitumor effects. Int Immunol 31:187-198

70. Lee KH, Hsu EC, Guh JH, Yang HC, Wang D, Kulp SK, Shapiro CL, Chen CS (2011) Targeting energy metabolic and oncogenic signaling pathways in triple-negative breast cancer by a novel adenosine monophosphate-activated protein kinase (AMPK) activator. J Biol Chem 286:39247-39258

71. Hillmer EJ, Zhang H, Li HS, Watowich SS (2016) STAT3 signaling in immunity. Cytokine Growth Factor Rev 31:1-15

72. Yan D, Yang Q, Shi M, Zhong L, Wu C, Meng T, Yin H, Zhou J (2013) Polyunsaturated fatty acids promote the expansion of myeloid-derived suppressor cells by activating the JAK/STAT3 pathway. Eur J Immunol 43:2943-2955

73. Vasquez-Dunddel D, Pan F, Zeng Q, Gorbounov M, Albesiano E, Fu J, Blosser RL, Tam AJ, Bruno T, Zhang H, Pardoll D, Kim Y (2013) STAT3 regulates arginase-I in myeloid-derived suppressor cells from cancer patients. J Clin Invest 123:1580-1589

74. Yu J, Wang Y, Yan F, Zhang P, Li H, Zhao H, Yan C, Yan F, Ren X (2014) Noncanonical NF-kB activation mediates STAT3stimulated IDO upregulation in myeloid-derived suppressor cells in breast cancer. J Immunol 193:2574-2586
75. Wu L, Deng Z, Peng Y, Han L, Liu J, Wang L, Li B, Zhao J, Jiao S, Wei H (2017) Ascites-derived IL-6 and IL-10 synergistically expand $\mathrm{CD}_{14}^{+} \mathrm{HLA}^{-} \mathrm{DR}^{-}$/low myeloid-derived suppressor cells in ovarian cancer patients. Oncotarget 8:76843-76856

76. Thorn M, Guha P, Cunetta M, Espat NJ, Miller G, Junghans RP, Katz SC (2016) Tumor-associated GM-CSF overexpression induces immunoinhibitory molecules via STAT3 in myeloidsuppressor cells infiltrating liver metastases. Cancer Gene Ther 23:188-198

77. Kumar V, Cheng P, Condamine T, Mony S, Languino LR, McCaffrey JC, Hockstein N, Guarino M, Masters G, Penman E, Denstman F, Xu X, Altieri DC, Du H, Yan C, Gabrilovich DI (2016) CD45 phosphatase inhibits STAT3 transcription factor activity in myeloid cells and promotes tumor-associated macrophage differentiation. Immunity 44:303-315

78. Ko JS, Rayman P, Ireland J, Swaidani S, Li G, Bunting KD, Rini B, Finke JH, Cohen PA (2010) Direct and differential suppression of myeloid-derived suppressor cell subsets by sunitinib is compartmentally constrained. Cancer Res 70:3526-3536

79. Banerjee S, Biehl A, Gadina M, Hasni S, Schwartz DM (2017) JAK-STAT signaling as a target for inflammatory and autoimmune diseases: current and future prospects. Drugs 77:521-546

80. Meares GP, Qin H, Liu Y, Holdbrooks AT, Benveniste EN (2013) AMP-activated protein kinase restricts IFN- $\gamma$ signaling. J Immunol 190:372-380

81. Nerstedt A, Johansson A, Andersson CX, Cansby E, Smith U, Mahlapuu M (2010) AMP-activated protein kinase inhibits IL-6stimulated inflammatory response in human liver cells by suppressing phosphorylation of signal transducer and activator of transcription 3 (STAT3). Diabetologia 53:2406-2416

82. Lu J, Zhang L, Chen X, Lu Q, Yang Y, Liu J, Ma X (2014) SIRT1 counteracted the activation of STAT3 and NF- $\mathrm{KB}$ to repress the gastric cancer growth. Int J Clin Exp Med 7:5050-5058

83. He C, Li H, Viollet B, Zou MH, Xie Z (2015) AMPK suppresses vascular inflammation in vivo by inhibiting signal transducer and activator of transcription-1. Diabetes 64:4285-4297

84. Lu R, Zhang YG, Sun J (2017) STAT3 activation in infection and infection-associated cancer. Mol Cell Endocrinol 451:80-87

85. Speirs C, Williams JJL, Riches K, Salt IP, Palmer TM (2018) Linking energy sensing to suppression of JAK-STAT signalling: a potential route for repurposing AMPK activators? Pharmacol Res 128:88-100

86. Condamine T, Gabrilovich DI (2011) Molecular mechanisms regulating myeloid-derived suppressor cell differentiation and function. Trends Immunol 32:19-25

87. Oh H, Grinberg-Bleyer Y, Liao W, Maloney D, Wang P, Wu Z, Wang J, Bhatt DM, Heise N, Schmid RM, Hayden MS, Klein U, Rabadan R, Ghosh S (2017) An NF-kB transcription-factordependent lineage-specific transcriptional program promotes regulatory $T$ cell identity and function. Immunity $47: 450-465$

88. Sinha P, Okoro C, Foell D, Freeze HH, Ostrand-Rosenberg S, Srikrishna G (2008) Proinflammatory S100 proteins regulate the accumulation of myeloid-derived suppressor cells. J Immunol 181:4666- 4675

89. Parker KH, Sinha P, Horn LA, Clements VK, Yang H, Li J, Tracey KJ, Ostrand-Rosenberg S (2014) HMGB1 enhances immune suppression by facilitating the differentiation and suppressive activity of myeloid-derived suppressor cells. Cancer Res 74:5723-5733

90. Karin M, Greten FR (2005) NF-kB: linking inflammation and immunity to cancer development and progression. Nat Rev Immunol 5:749-759

91. Bunt SK, Sinha P, Clements VK, Leips J, Ostrand-Rosenberg S (2006) Inflammation induces myeloid-derived suppressor cells that facilitate tumor progression. J Immunol 176:284-290

92. Zhang H, Huang Y, Wang S, Fu R, Guo C, Wang H, Zhao J, Gaskin F, Chen J, Yang N, Fu SM (2015) Myeloid-derived 
suppressor cells contribute to bone erosion in collagen-induced arthritis by differentiating to osteoclasts. J Autoimmun 65:82-89

93. Hong EH, Chang SY, Lee BR, Kim YS, Lee JM, Kang CY, Kweon MN, Ko HJ (2013) Blockade of Myd88 signaling induces antitumor effects by skewing the immunosuppressive function of myeloid-derived suppressor cells. Int J Cancer 132:2839-2848

94. Ray A, Chakraborty K, Ray P (2013) Immunosuppressive MDSCs induced by TLR signaling during infection and role in resolution of inflammation. Front Cell Infect Microbiol 3:52

95. Wang J, Shirota Y, Bayik D, Shirota H, Tross D, Gulley JL, Wood LV, Berzofsky JA, Klinman DM (2015) Effect of TLR agonists on the differentiation and function of human monocytic myeloidderived suppressor cells. J Immunol 194:4215-4221

96. Kawai T, Akira S (2007) Signaling to NF-kB by Toll-like receptors. Trends Mol Med 13:460-469

97. Fan Y, Mao R, Yang J (2013) NF-kB and STAT3 signaling pathways collaboratively link inflammation to cancer. Protein Cell 4 : 176-185

98. Rameshrad M, Soraya H, Maleki-Dizaji N, Vaez H, Garjani A (2016) A-769662, a direct AMPK activator, attenuates lipopolysaccharide-induced acute heart and lung inflammation in rats. Mol Med Rep 13:2843-2849

99. Vaez H, Najafi M, Rameshrad M, Toutounchi NS, Garjani M, Barar J, Garjani A (2016) AMPK activation by metformin inhibits local innate immune responses in the isolated rat heart by suppression of TLR 4-related pathway. Int Immunopharmacol 40:501507

100. Cordero MD, Williams MR, Ryffel B (2018) AMP-activated protein kinase regulation of the NLRP3 inflammasome during aging. Trends Endocrinol Metab 29:8-17

101. Bauernfeind FG, Horvath G, Stutz A, Alnemri ES, MacDonald K, Speert D, Fernandes-Alnemri T, Wu J, Monks BG, Fitzgerald KA, Hornung V, Latz E (2009) Cutting edge: NF- $\mathrm{BB}$ activating pattern recognition and cytokine receptors license NLRP3 inflammasome activation by regulating NLRP3 expression. J Immunol 183:787-791

102. van Deventer HW, Burgents JE, Wu QP, Woodford RM, Brickey WJ, Allen IC, McElvania-Tekippe E, Serody JS, Ting JP (2010) The inflammasome component NLRP3 impairs antitumor vaccine by enhancing the accumulation of tumor-associated myeloid-derived suppressor cells. Cancer Res 70:10161-10169

103. Chen L, Huang CF, Li YC, Deng WW, Mao L, Wu L, Zhang WF, Zhang L, Sun ZJ (2018) Blockage of the NLRP3 inflammasome by MCC950 improves anti-tumor immune responses in head and neck squamous cell carcinoma. Cell Mol Life Sci 75:2045-2058

104. Salminen A, Ojala J, Kaarniranta K, Kauppinen A (2012) Mitochondrial dysfunction and oxidative stress activate inflammasomes: impact on the aging process and age-related diseases. Cell Mol Life Sci 69:2999-3013

105. Huber R, Pietsch D, Panterodt T, Brand K (2012) Regulation of $\mathrm{C} / \mathrm{EBP} \beta$ and resulting functions in cells of the monocytic lineage. Cell Signal 24:1287-1296

106. van der Krieken SE, Popeijus HE, Mensink RP, Plat J (2016) CCAAT/enhancer binding protein $\beta$ in relation to ER stress, inflammation, and metabolic disturbances. Biomed Res Int 2015:324815

107. Marigo I, Bosio E, Solito S, Mesa C, Fernandez A, Dolcetti L, Ugel S, Sonda N, Bicciato S, Falisi E, Calabrese F, Basso G, Zanovello P, Cozzi E, Mandruzzato S, Bronte V (2010) Tumorinduced tolerance and immune suppression depend on the $\mathrm{C} / \mathrm{EBP} \beta$ transcription factor. Immunity 32:790-802

108. Dai J, Kumbhare A, Youssef D, Yao ZQ, McCall CE, El Gazzar M (2017) Expression of C/EBP $\beta$ in myeloid progenitors during sepsis promotes immunosuppression. Mol Immunol 91:165-172

109. McPeak MB, Youssef D, Williams DA, Pritchett CL, Yao ZQ, McCall CE, El Gazzar M (2017) Frontline science: myeloid cellspecific deletion of Cebpb decreases sepsis-induced immunosuppression in mice. J Leukoc Biol 102:191-200
110. Choy L, Derynck R (2003) Transforming growth factor- $\beta$ inhibits adipocyte differentiation by Smad3 interacting with CCAAT/ enhancer-binding protein $(\mathrm{C} / \mathrm{EBP})$ and repressing $\mathrm{C} / \mathrm{EBP}$ transactivation function. J Biol Chem 278:9609-9619

111. Abraham S, Sweet T, Khalili K, Sawaya BE, Amini S (2009) Evidence for activation of the TGF- $\beta 1$ promoter by $\mathrm{C} / \mathrm{EBP} \beta$ and its modulation by Smads. J Interf Cytokine Res 29:1-7

112. Bijland S, Mancini SJ, Salt IP (2013) Role of AMP-activated protein kinase in adipose tissue metabolism and inflammation. Clin Sci (Lond) 124:491-507

113. Lin F, Ribar TJ, Means AR (2011) The $\mathrm{Ca}^{+} /$calmodulin-dependent protein kinase kinase, CaMKK2, inhibits preadipocyte differentiation. Endocrinology 152:3668-3679

114. Wang SJ, Lu WY, Liu KY (2017) Adiponectin receptor agonist AdipoRon suppresses adipogenesis in $\mathrm{C} 3 \mathrm{H} 10 \mathrm{~T} 1 / 2$ cells through the adenosine monophosphate-activated protein kinase signaling pathway. Mol Med Rep 16:7163-7169

115. Choudhury M, Qadri I, Rahman SM, Schroeder-Gloeckler J, Janssen RC, Friedman JE (2011) C/EBP $\beta$ is AMP kinase sensitive and up-regulates PEPCK in response to ER stress in hepatoma cells. Mol Cell Endocrinol 331:102-108

116. Zhang Y, Liu X, Zhang L, Li X, Zhou Z, Jiao L, Shao Y, Li M, Leng B, Zhou Y, Liu T, Liu Q, Shan H, Du Z (2018) Metformin protects against $\mathrm{H} 2 \mathrm{O} 2$-induced cardiomyocyte injury by inhibiting the miR1a-3p/GRP94 pathway. Mol Ther Nucleic Acids 13:189-197

117. Matsuda T, Takahashi H, Mieda Y, Shimizu S, Kawamoto T, Matsuura Y, Takai T, Suzuki E, Kanno A, Koyanagi-Kimura M, Asahara S, Bartolome A, Yokoi N, Inoue H, Ogawa W, Seino S, Kido Y (2015) Regulation of pancreatic $\beta$ cell mass by crossinteraction between CCAAT enhancer binding protein $\beta$ induced by endoplasmic reticulum stress and AMP-activated protein kinase activity. PLoS One 10:e0130757

118. Lee BR, Chang SY, Hong EH, Kwon BE, Kim HM, Kim YJ, Lee J, Cho HJ, Cheon JH, Ko HJ (2014) Elevated endoplasmic reticulum stress reinforced immunosuppression in the tumor microenvironment via myeloid-derived suppressor cells. Oncotarget 5:12331-12345

119. Yang Y, Liu L, Naik I, Braunstein Z, Zhong J, Ren B (2017) Transcription factor C/EBP homologous protein in health and diseases. Front Immunol 8:1612

120. Chornoguz O, Grmai L, Sinha P, Artemenko KA, Zubarev RA, Ostrand-Rosenberg S (2011) Proteomic pathway analysis reveals inflammation increases myeloid-derived suppressor cell resistance to apoptosis. Mol Cell Proteomics 10:M110.002980

121. Thevenot PT, Sierra RA, Raber PL, Al-Khami AA, Trillo-Tinoco J, Zarreii P, Ochoa AC, Cui Y, Del Valle L, Rodriguez PC (2014) The stress-response sensor chop regulates the function and accumulation of myeloid-derived suppressor cells in tumors. Immunity 41:389-401

122. Shang W, Tang Z, Gao Y, Qi H, Su X, Zhang Y, Yang R (2017) LncRNA RNCR3 promotes Chop expression by sponging miR185-5p during MDSC differentiation. Oncotarget 8:111754-111769

123. Terai K, Hiramoto Y, Masaki M, Sugiyama S, Kuroda T, Hori M, Kawase I, Hirota H (2005) AMP-activated protein kinase protects cardiomyocytes against hypoxic injury through attenuation of endoplasmic reticulum stress. Mol Cell Biol 25:9554-9575

124. Kim H, Moon SY, Kim JS, Baek CH, Kim M, Min JY, Lee SK (2015) Activation of AMP-activated protein kinase inhibits ER stress and renal fibrosis. Am J Physiol Ren Physiol 308:F226-F236

125. Dai X, Ding Y, Liu Z, Zhang W, Zou MH (2016) Phosphorylation of CHOP (C/EBP homologous protein) by the AMP-activated protein kinase $\alpha 1$ in macrophages promotes CHOP degradation and reduces injury-induced neointimal disruption in vivo. Circ Res 119:1089-1100

126. Wortel IMN, van der Meer LT, Kilberg MS, van Leeuwen FN (2017) Surviving stress: modulation of ATF4-mediated stress responses in normal and malignant cells. Trends Endocrinol Metab 28:794-806 
127. Kumar V, Gabrilovich DI (2014) Hypoxia-inducible factors in regulation of immune responses in tumour microenvironment. Immunology 143:512-519

128. Cummins EP, Keogh CE, Crean D, Taylor CT (2016) The role of HIF in immunity and inflammation. Mol Asp Med 47-48:24-34

129. Corzo CA, Condamine T, Lu L, Cotter MJ, Youn JI, Cheng P, Cho HI, Celis E, Quiceno DG, Padhya T, McCaffrey TV, McCaffrey JC, Gabrilovich DI (2010) HIF-1 $\alpha$ regulates function and differentiation of myeloid-derived suppressor cells in the tumor microenvironment. J Exp Med 207:2439-2453

130. Noman MZ, Desantis G, Janji B, Hasmim M, Karray S, Dessen P, Bronte V, Chouaib S (2014) PD-L1 is a novel direct target of HIF$1 \alpha$, and its blockade under hypoxia enhanced MDSC-mediated T cell activation. J Exp Med 211:781-790

131. Li J, Wang L, Chen X, Li L, Li Y, Ping Y, Huang L, Yue D, Zhang Z, Wang F, Li F, Yang L, Huang J, Yang S, Li H, Zhao X, Dong W, Yan Y, Zhao S, Huang B, Zhang B, Zhang Y (2017) CD39/CD73 upregulation on myeloid-derived suppressor cells via TGF- $\beta$ mTOR-HIF-1 signaling in patients with non-small cell lung cancer. Oncoimmunology 6:e1320011

132. Ryzhov S, Novitskiy SV, Goldstein AE, Biktasova A, Blackburn MR, Biaggioni I, Dikov MM, Feoktistov I (2011) Adenosinergic regulation of the expansion and immunosuppressive activity of $\mathrm{CD} 1 \mathrm{~b}^{+} \mathrm{Gr} 1^{+}$cells. J Immunol 187:6120-6129

133. Salminen A, Kaarniranta K, Kauppinen A (2016) AMPK and HIF signaling pathways regulate both longevity and cancer growth: the good news and the bad news about survival mechanisms. Biogerontology 17:655-680

134. Land SC, Tee AR (2007) Hypoxia-inducible factor $1 \alpha$ is regulated by the mammalian target of rapamycin (mTOR) via an mTOR signaling motif. J Biol Chem 282:20534-20543

135. Rius J, Guma M, Schachtrup C, Akassoglou K, Zinkernagel AS, Nizet V, Johnson RS, Haddad GG, Karin M (2008) NF-kB links innate immunity to the hypoxic response through transcriptional regulation of HIF-1 $\alpha$. Nature 453:807-811

136. Joo HY, Yun M, Jeong J, Park ER, Shin HJ, Woo SR, Jung JK, Kim YM, Park JJ, Kim J, Lee KH (2015) SIRT1 deacetylates and stabilizes hypoxia-inducible factor- $1 \alpha(\mathrm{HIF}-1 \alpha)$ via direct interactions during hypoxia. Biochem Biophys Res Commun 462:294-300

137. Chen S, Yin C, Lao T, Liang D, He D, Wang C, Sang N (2015) AMPK-HDAC5 pathway facilitates nuclear accumulation of HIF$1 \alpha$ and functional activation of HIF-1 by deacetylating Hsp70 in the cytosol. Cell Cycle 14:2520-2536

138. Li L, Wang L, Li J, Fan Z, Yang L, Zhang Z, Zhang C, Yue D, Qin G, Zhang T, Li F, Chen X, Ping Y, Wang D, Gao Q, He Q, Huang L, Li H, Huang J, Zhao X, Xue W, Sun Z, Lu J, Yu JJ, Zhao J, Zhang B, Zhang Y (2018) Metformin-induced reduction of CD39 and CD73 blocks myeloid-derived suppressor cell activity in patients with ovarian cancer. Cancer Res 78:1779-1791

139. Cha JH, Yang WH, Xia W, Wei Y, Chan LC, Lim SO, Li CW, Kim T, Chang SS, Lee HH, Hsu JL, Wang HL, Kuo CW, Chang WC, Hadad S, Purdie CA, McCoy AM, Cai S, Tu Y, Litton JK, Mittendorf EA, Moulder SL, Symmans WF, Thompson AM, Piwnica-Worms H, Chen CH, Khoo KH, Hung MC (2018) Metformin promotes antitumor immunity via endoplasmicreticulum-associated degradation of PD-L1. Mol Cell 71:606-620

140. Ahmed SM, Luo L, Namani A, Wang XJ, Tang X (2017) Nrf2 signaling pathway: pivotal roles in inflammation. Biochim Biophys Acta Mol basis Dis 1863:585-597

141. Zimmermann K, Baldinger J, Mayerhofer B, Atanasov AG, Dirsch VM, Heiss EH (2015) Activated AMPK boosts the Nrf2/HO-1 signaling axis-A role for the unfolded protein response. Free Radic Biol Med 88:417-426

142. Joo MS, Kim WD, Lee KY, Kim JH, Koo JH, Kim SG (2016) AMPK facilitates nuclear accumulation of Nrf2 by phosphorylating at serine 550. Mol Cell Biol 36:1931-1942
143. Beury DW, Carter KA, Nelson C, Sinha P, Hanson E, Nyandjo M, Fitzgerald PJ, Majeed A, Wali N, Ostrand-Rosenberg S (2016) Myeloid-derived suppressor cell survival and function are regulated by the transcription factor Nrf2. J Immunol 196:3470-3478

144. Ohl K, Fragoulis A, Klemm P, Baumeister J, Klock W, Verjans E, Böll S, Möllmann J, Lehrke M, Costa I, Denecke B, Schippers A, Roth J, Wagner N, Wruck C, Tenbrock K (2018) Nrf2 is a central regulator of metabolic reprogramming of myeloid-derived suppressor cells in steady state and sepsis. Front Immunol 9:1552

145. Buck MD, Sowell RT, Kaech SM, Pearce EL (2017) Metabolic instruction of immunity. Cell 169:570-586

146. Stienstra R, Netea-Maier RT, Riksen NP, Joosten LAB, Netea MG (2017) Specific and complex reprogramming of cellular metabolism in myeloid cells during innate immune responses. Cell Metab 26:142-156

147. Porta C, Marino A, Consonni FM, Bleve A, Mola S, Storto M, Riboldi E, Sica A (2018) Metabolic influence on the differentiation of suppressive myeloid cells in cancer. Carcinogenesis 39: 1095-1104

148. Liberti MV, Locasale JW (2016) The Warburg effect: how does it benefit cancer cells? Trends Biochem Sci 41:211-218

149. Palsson-McDermott EM, O'Neill LA (2013) The Warburg effect then and now: from cancer to inflammatory diseases. Bioessays 35:965-973

150. Bar-Or D, Carrick M, Tanner A 2nd, Lieser MJ, Rael LT, Brody E (2018) Overcoming the Warburg effect: is it the key to survival in sepsis? J Crit Care 43:197-201

151. Chen Z, Liu M, Li L, Chen L (2018) Involvement of the Warburg effect in non-tumor diseases processes. J Cell Physiol 233:28392849

152. Menk AV, Scharping NE, Moreci RS, Zeng X, Guy C, Salvatore S, Bae H, Xie J, Young HA, Wendell SG, Delgoffe GM (2018) Early TCR signaling induces rapid aerobic glycolysis enabling distinct acute T cell effector functions. Cell Rep 22:1509-1521

153. Kouidhi S, Noman MZ, Kieda C, Elgaaied AB, Chouaib S (2016) Intrinsic and tumor microenvironment-induced metabolism adaptations of $\mathrm{T}$ cells and impact on their differentiation and function. Front Immunol 7:114

154. Sun S, Li H, Chen J, Qian Q (2017) Lactic acid: no longer an inert and end-product of glycolysis. Physiology (Bethesda) 32:453-463

155. Nolt B, Tu F, Wang X, Ha T, Winter R, Williams DL, Li C (2018) Lactate and immunosuppression in sepsis. Shock 49:120-125

156. Seth P, Csizmadia E, Hedblom A, Vuerich M, Xie H, Li M, Longhi MS, Wegiel B (2017) Deletion of lactate dehydrogenaseA in myeloid cells triggers antitumor immunity. Cancer Res 77: 3632-3643

157. Chirasani SR, Leukel P, Gottfried E, Hochrein J, Stadler K, Neumann B, Oefner PJ, Gronwald W, Bogdahn U, Hau P, Kreutz M, Grauer OM (2013) Diclofenac inhibits lactate formation and efficiently counteracts local immune suppression in a murine glioma model. Int J Cancer 132:843-853

158. Husain Z, Huang Y, Seth P, Sukhatme VP (2013) Tumor-derived lactate modifies antitumor immune response: effect on myeloidderived suppressor cells and NK cells. J Immunol 191:1486-1495

159. Cai TT, Ye SB, Liu YN, He J, Chen QY, Mai HQ, Zhang CX, Cui J, Zhang XS, Busson P, Zeng YX, Li J (2017) LMP1-mediated glycolysis induces myeloid-derived suppressor cell expansion in nasopharyngeal carcinoma. PLoS Pathog 13:e1006503

160. Brooks GA (2018) The science and translation of lactate shuttle theory. Cell Metab 27:757-785

161. Demaria M, Poli V (2012) PKM2, STAT3 and HIF-1 $\alpha$ : the Warburg's vicious circle. JAKSTAT 1:194-196

162. Hawkins KE, Joy S, Delhove JM, Kotiadis VN, Fernandez E, Fitzpatrick LM, Whiteford JR, King PJ, Bolanos JP, Duchen MR, Waddington SN, McKay TR (2016) NRF2 orchestrates the 
metabolic shift during induced pluripotent stem cell reprogramming. Cell Rep 14:1883-1891

163. Makki K, Taront S, Molendi-Coste O, Bouchaert E, Neve B, Eury E, Lobbens S, Labalette M, Duez H, Staels B, Dombrowicz D, Froguel P, Wolowczuk I (2014) Beneficial metabolic effects of rapamycin are associated with enhanced regulatory cells in dietinduced obese mice. PLoS One 9:e92684

164. Chen X, Zhang Z, Bi Y, Fu Z, Gong P, Li Y, Yu Q, Jia A, Wang J, Xue L, Yang H, Liu G (2016) mTOR signaling disruption from myeloid-derived suppressive cells protects against immunemediated hepatic injury through the HIF $1 \alpha$-dependent glycolytic pathway. J Leukoc Biol 100:1349-1362

165. Deng Y, Yang J, Luo F, Qian J, Liu R, Zhang D, Yu H, Chu Y (2018) mTOR-mediated glycolysis contributes to the enhanced suppressive function of murine tumor-infiltrating monocytic myeloid-derived suppressor cells. Cancer Immunol Immunother 67:1355-1364

166. Liu G, Bi Y, Shen B, Yang H, Zhang Y, Wang X, Liu H, Lu Y, Liao J, Chen X, Chu Y (2014) SIRT1 limits the function and fate of myeloid-derived suppressor cells in tumors by orchestrating HIF$1 \alpha$-dependent glycolysis. Cancer Res 74:727-737

167. Hammami I, Chen J, Bronte V, DeCrescenzo G, Jolicoeur M (2012) L-glutamine is a key parameter in the immunosuppression phenomenon. Biochem Biophys Res Commun 425:724-729

168. Yang C, Ko B, Hensley CT, Jiang L, Wasti AT, Kim J, Sudderth J, Calvaruso MA, Lumata L, Mitsche M, Rutter J, Merritt ME, DeBerardinis RJ (2014) Glutamine oxidation maintains the TCA cycle and cell survival during impaired mitochondrial pyruvate transport. Mol Cell 56:414-424

169. Morikawa N, Tachibana M, Ago Y, Goda H, Sakurai F, Mizuguchi H (2018) LY341495, an mGluR2/3 antagonist, regulates the immunosuppressive function of myeloid-derived suppressor cells and inhibits melanoma tumor growth. Biol Pharm Bull 41:1866-1869

170. Fritsche K (2006) Fatty acids as modulators of the immune response. Annu Rev Nutr 26:45-73

171. Lochner M, Berod L, Sparwasser T (2015) Fatty acid metabolism in the regulation of $\mathrm{T}$ cell function. Trends Immunol 36:81-91

172. Kim W, Khan NA, McMurray DN, Prior IA, Wang N, Chapkin RS (2010) Regulatory activity of polyunsaturated fatty acids in T-cell signaling. Prog Lipid Res 49:250-261

173. Shaikh SR, Edidin M (2007) Immunosuppressive effects of polyunsaturated fatty acids on antigen presentation by human leukocyte antigen class I molecules. J Lipid Res 48:127-138

174. Kalinski P (2012) Regulation of immune responses by prostaglandin E2. J Immunol 188:21-28

175. Xia S, Li X, Cheng L, Han M, Zhang M, Liu X, Xu H, Zhang M, Shao Q, Qi L (2014) Chronic intake of high fish oil diet induces myeloid-derived suppressor cells to promote tumor growth. Cancer Immunol Immunother 63:663-673

176. Lin A, Wang G, Zhao H, Zhang Y, Han Q, Zhang C, Tian Z, Zhang J (2015) TLR4 signaling promotes a COX-2/PGE2/ STAT3 positive feedback loop in hepatocellular carcinoma (HCC) cells. Oncoimmunology 5:e1074376

177. Obermajer N, Wong JL, Edwards RP, Odunsi K, Moysich K, Kalinski P (2012) PGE(2)-driven induction and maintenance of cancer-associated myeloid-derived suppressor cells. Immunol Investig 41:635-657

178. Lee YK, Park SY, Kim YM, Lee WS, Park OJ (2009) AMP kinase/ cyclooxygenase-2 pathway regulates proliferation and apoptosis of cancer cells treated with quercetin. Exp Mol Med 41:201-207

179. Veltman JD, Lambers ME, van Nimwegen M, Hendriks RW, Hoogsteden HC, Aerts JG, Hegmans JP (2010) COX-2 inhibition improves immunotherapy and is associated with decreased numbers of myeloid-derived suppressor cells in mesothelioma. Celecoxib influences MDSC function. BMC Cancer 10:464

180. Ostrand-Rosenberg S (2018) Myeloid derived-suppressor cells: their role in cancer and obesity. Curr Opin Immunol 51:68-75

181. Hossain F, Al-Khami AA, Wyczechowska D, Hernandez C, Zheng L, Reiss K, Valle LD, Trillo-Tinoco J, Maj T, Zou W, Rodriguez PC, Ochoa AC (2015) Inhibition of fatty acid oxidation modulates immunosuppressive functions of myeloid-derived suppressor cells and enhances cancer therapies. Cancer Immunol Res 3:1236-1247

182. Al-Khami AA, Zheng L, Del Valle L, Hossain F, Wyczechowska D, Zabaleta J, Sanchez MD, Dean MJ, Rodriguez PC, Ochoa AC (2017) Exogenous lipid uptake induces metabolic and functional reprogramming of tumor-associated myeloid-derived suppressor cells. Oncoimmunology 6:e1344804

183. Samovski D, Sun J, Pietka T, Gross RW, Eckel RH, Su X, Stahl PD, Abumrad NA (2015) Regulation of AMPK activation by CD36 links fatty acid uptake to $\beta$-oxidation. Diabetes 64:353-359

184. Guertin DA, Sabatini DM (2007) Defining the role of mTOR in cancer. Cancer Cell 12:9-22

185. Yu H, Lee H, Herrmann A, Buettner R, Jove R (2014a) Revisiting STAT3 signalling in cancer: new and unexpected biological functions. Nat Rev Cancer 14:736-746

186. Kim MH, Minton AZ, Agrawal V (2009) C/EBP $\beta$ regulates metastatic gene expression and confers TNF- $\alpha$ resistance to prostate cancer cells. Prostate 69:1435-1447

187. Semenza GL (2003) Targeting HIF-1 for cancer therapy. Nat Rev Cancer 3:721-732

188. Rena G, Hardie DG, Pearson ER (2017) The mechanisms of action of metformin. Diabetologia 60:1577-1585

189. Kumase F, Takeuchi K, Morizane Y, Suzuki J, Matsumoto H, Kataoka K, Al-Moujahed A, Maidana DE, Miller JW, Vavvas DG (2016) AMPK-activated protein kinase suppresses Ccr2 expression by inhibiting the NF-KB pathway in RAW264.7 macrophages. PLoS One 11:e147279

190. Ye J, Zhu N, Sun R, Liao W, Fan S, Shi F, Lin H, Jiang S, Ying Y (2018) Metformin inhibits chemokine expression through the AMPK/NF-KB signaling pathway. J Interf Cytokine Res 38:363-369

191. Chen S, Zhu X, Lai X, Xiao T, Wen A, Zhang J (2014) Combined cancer therapy with non-conventional drugs: all roads lead to AMPK. Mini-Rev Med Chem 14:642-654

192. Canto C, Auwerx J (2011) Calorie restriction: is AMPK a key sensor and effector? Physiology (Bethesda) 26:214-224

193. Salminen A, Kauppinen A, Kaarniranta K (2017) FGF21 activates AMPK signaling: impact on metabolic regulation and the aging process. J Mol Med (Berl) 95:123-131

194. Piskovatska V, Stefanyshyn N, Storey KB, Vaiserman AM, Lushchak O (2019) Metformin as a geroprotector: experimental and clinical evidence. Biogerontology 20:33-48

195. Welte T, Kim IS, Tian L, Gao X, Wang H, Li J, Holdman XB, Herschkowitz JI, Pond A, Xie G, Kurley S, Nguyen T, Liao L, Dobrolecki LE, Pang L, Mo Q, Edwards DP, Huang S, Xin L, Xu J, Li Y, Lewis MT, Wang T, Westbrook TF, Rosen JM, Zhang XH (2016) Oncogenic mTOR signalling recruits myeloid-derived suppressor cells to promote tumour initiation. Nat Cell Biol 18:632-644

196. Jacquel A, Luciano F, Robert G, Auberger P (2018) Implication and regulation of AMPK during physiological and pathological myeloid differentiation. Int J Mol Sci 19:2991

Publisher's note Springer Nature remains neutral with regard to jurisdictional claims in published maps and institutional affiliations. 